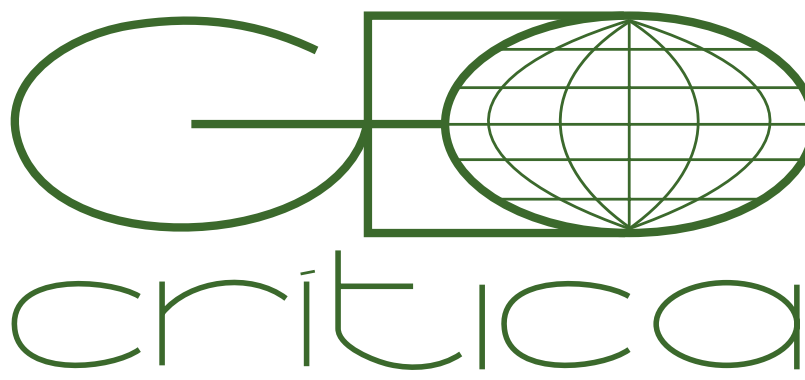

\section{Scripta Nova}

Revista Electrónica de Geografía y Ciencias Sociales Universitat de Barcelona

1 de noviembre de 2020

\title{
CIUDAD POSTINDUSTRIAL Y DINÁMICAS SOCIO-RESIDENCIALES EN ESPAÑA: UN ANÁLISIS COMPARATIVO DE CINCO METRÓPOLIS
}

\author{
Sergio Porcel López \\ sergio.porcel@uab.cat \\ Fernando Antón Alonso \\ fernando.anton.alonso@uab.cat \\ Institut d'Estudis Regionals i Metropolitans de Barcelona
}

Recibido: 31 julio 2019; Devuelto para correcciones: 6 marzo 2020; Aceptado: 7 julio 2020

\begin{abstract}
Ciudad postindustrial y dinámicas socio-residenciales en España: un análisis comparativo de cinco metrópolis (Resumen)

El debate sobre los efectos socio-residenciales de la globalización y la desindustrialización en las grandes ciudades ha marcado desde los años 90 la producción científica en torno a la estructuración socio-residencial urbana. Esta investigación parte del modelo teórico Quartered City, surgido en ese debate, para estudiar la evolución de las principales metrópolis españolas. Los objetivos son constatar si la estructura socio-residencial se está fragmentando y polarizando cada vez más y si estos procesos están asociados a factores vinculados con la desindustrialización y la globalización. En la misma línea, también se analiza la incidencia de otros factores demográficos y geográficos y del impacto de la crisis. Los resultados avalan la capacidad explicativa de este modelo teórico en el contexto español, confirmando un aumento de la fragmentación urbana y de la polarización socio-residencial en la mayoría de metrópolis estudiadas.
\end{abstract}

Palabras clave: desigualdad social, estructuración socio-residencial, ciudad cuarteada

\section{Post-industrial city and socio-residential dynamics in Spain: a comparative analysis of five metropolises (Abstract)}

The debate on the socio-residential effects of globalization and deindustrialization in large cities has marked since the 90 s the scientific production around the urban socio-residential structuring. This research is based on the Quartered City theoretical model, emerged in that debate, to study the evolution of the main Spanish metropolis. The objectives are to verify if the socio-residential structure is increasingly fragmenting and polarising and whether both processes are associated with factors linked to deindustrialization and globalisation. In the same vein, the incidence of other demographic, geographic factors and the impact of the crisis is also tested. The results support the explanatory capacity of this theoretical model in the Spanish context, confirming an increase in urban fragmentation and socio-residential polarisation in most of the metropolises studied.

Key words: social inequality, socio-residential structuring, quartered city 
Los efectos que han desencadenado la desindustrialización y la globalización en las dinámicas de estructuración socio-residencial de las grandes ciudades se vienen estudiando en el ámbito de los estudios urbanos desde finales de los años 80. Aunque se constatan diferencias relevantes entre los contextos norteamericano y europeo, la mayoría de estas investigaciones señalan que estos procesos estructurales contribuyen a un aumento de la división del espacio urbano y de la desigualdad social en las urbes. Desde el punto de vista teórico, el debate en torno a la explicación de este fenómeno ha estado marcado principalmente por la existencia de dos modelos explicativos, no necesariamente contrapuestos, pero sí diferenciados. El modelo de ciudad dual (Dual City)1, que se ajusta más al contexto norteamericano y, en general, para otras ciudades enmarcadas en regímenes neoliberales, y el modelo ciudad cuarteada (Quartered City) ${ }^{2}$, pensado más bien para dar respuesta a la complejidad de la realidad urbana europea (aunque no sólo), donde el Estado juega un papel más relevante en términos redistributivos.

Partiendo de este debate, la presente investigación se centra en el análisis de las dinámicas de estructuración socio-residencial que se han producido durante la última década (2001-2011) en las principales metrópolis españolas (Madrid, Barcelona, Valencia, Bilbao y Sevilla). Este análisis se realiza adoptando el modelo de ciudad cuarteada como referencia, a partir del cual se formulan las hipótesis y se define la aproximación empírica. De hecho, más allá de los resultados obtenidos, la propia operativización de este modelo teórico constituye, con sus limitaciones, una de las contribuciones más relevantes de este trabajo 3 . Por otro lado, la incorporación al análisis de cinco metrópolis españolas para realizar una mirada comparativa del contexto urbano español es otro de los elementos importantes de este estudio.

El artículo se estructura en varios apartados. En el primero se realiza un repaso sobre las principales cuestiones teóricas del debate ciudad dual y ciudad cuartea$d a$. En el segundo se explican las principales especificidades metodológicas que envuelven este trabajo, entre las cuales destaca, por un lado, el tratamiento del Censo de Población y Vivienda, 2011, y, por otro lado, la construcción de la tipología de áreas socio-residenciales a partir de lo que se ha denominado por los propios autores como "ecología factorial retroductiva". En los siguientes apartados se exponen los resultados de los análisis y se cierra el artículo con las principales conclusiones.

\section{Globalización, desindustrialización y ciudad: apuntes sobre el debate teórico}

Durante los años 80 emerge en el ámbito de los estudios urbanos una serie de investigaciones que, partiendo del estudio de la pobreza urbana, tratan directa o indirectamente las dinámicas de segregación residencial y de estructuración socio-residen-

\footnotetext{
1 Sassen, 1991.

2 Marcuse, 1989, 1993; Marcuse y van Kempen, 2000, 2002.

3 En el ámbito de la sociología urbana no es muy habitual realizar análisis empíricos siguiendo esquemas teóricos, cosa que sí ocurre en otros ámbitos de la sociología.
} 
cial de las ciudades norteamericanas. Las más destacables son las obras de Wilson ${ }^{4}$ y de Massey y Denton ${ }^{5}$, ambas centradas en el análisis de los procesos de conformación y transformación de los guetos de afroamericanos y en las consecuencias y los agravios sociales que sufre la población que reside en estos entornos residenciales 6 . Pero lo más relevante de sendas investigaciones en términos teóricos es que otorgan un gran peso explicativo a cómo el proceso de desindustrialización incide en la transformación de las formas urbanas. Este mismo enfoque es adoptado y enriquecido durante la década de los 90 por diversos autores, estableciéndose un fructífero debate acerca de los efectos que desencadenan tanto la desindustrialización como la globalización en la estructura socio-residencial de las grandes ciudades.

Este debate se inicia de la mano de Saskia Sassen, cuando concluye a principios de los 90 que la composición social de tres de las ciudades más importantes del mundo - Nueva York, Londres y Tokio- se está polarizando como consecuencia de los efectos de la desindustrialización y de la globalización 7 . Según la autora, la desindustrialización comporta un cambio en la demanda de mano de obra que afecta a la estructura ocupacional, incrementándose sobre todo los trabajadores cualificados del sector servicios, así como los no cualificados, lo que se traduce en una desigualdad creciente de los salarios de los trabajadores urbanos ${ }^{8}$. Sassen, además, remarca que, en el escenario globalizado, las grandes ciudades adquieren un papel relevante como actores territoriales y éste es uno de los principales motivos por los que en ellas se dejan notar con mayor intensidad los efectos de la desindustrialización y de la globalización`. La polarización urbana es una de las consecuencias más importantes, ya que es en las metrópolis donde se concentran los sectores productivos que comportan una mayor dispersión de ingresos, donde la elevada densidad de población asegura una intensa competencia por el empleo y donde existe también una mayor proporción de economía informal precaria. Finalmente, la autora plantea también que, en el plano espacial, todo este proceso de cambio económico estructural se traduce en un aumento de las dinámicas de segregación residencial entre clases sociales, donde los procesos de gentrificación, suburbanización y deterioro social de los barrios desfavorecidos se intensifican ${ }^{10}$.

Sassen explica así la producción de una nueva geografía de la centralidad y de la marginalidad que refleja las nuevas desigualdades y también las nuevas pautas que se desprenden del funcionamiento del sistema productivo capitalista postindustrial. Este fenómeno lo sintetiza en el concepto de ciudad dual (Dual City), que expresa la

4 Wilson, 1987.

5 Massey y Denton, 1993.

6 Un ejemplo más reciente de este tipo de estudios puede encontrarse en los trabajos realizados por Loïc Wacquant (2001) quien analiza de forma comparativa las transformaciones que se han producido en los guetos de afroamericanos en Chicago y las banlieues parisinas en el contexto postfordista.

7 Sassen, 1991.

8 Sassen, 1996.

9 Sassen, 1994.

10 Sassen, 1994. 
tendencia hacia la polarización en diferentes dimensiones de la realidad urbana, como en el uso del espacio, en el mercado de trabajo, en el mercado inmobiliario y en la estructura de consumo. Más allá de las críticas ${ }^{11}$ que suscita este modelo teórico, muchas de ellas relacionadas con la excesiva simplicidad de su planteamiento, resulta innegable su utilidad como punto de partida para formular hipótesis en estudios sobre segregación residencial, por ejemplo. Otros autores han reivindicado también su valor político, reclamando en este sentido la capacidad para denunciar las dinámicas de exclusión que se producen en las ciudades globalizadas ${ }^{12}$.

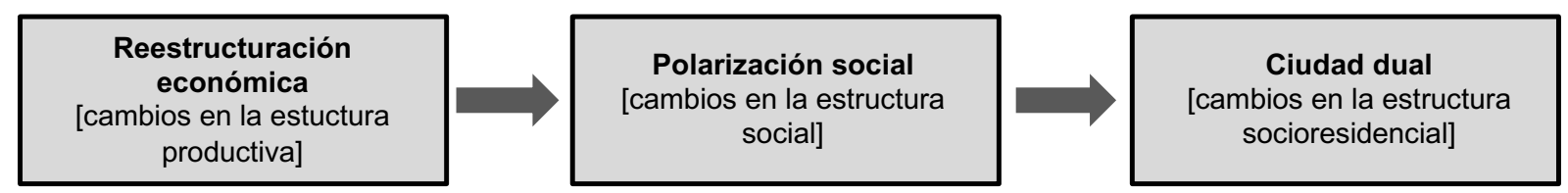

Gráfico 1. Modelo teórico de ciudad dual Fuente: Adaptación a partir de Eva van Kempen (1994).

Por otro lado, hay autores como Peter Marcuse y Ronald van Kempen que ofrecen un modelo teórico alternativo al de ciudad dual, que denominan ciudad cuarteada (Quartered City $)^{13}$. El rasgo distintivo de este modelo es que destaca el papel del Estado en la configuración de la estructuración socio-residencial de las ciudades. Desde este punto de vista, la acción del Estado tiene un efecto relevante en las dinámicas del mercado inmobiliario (legislación, sistema fiscal, etc.), en la construcción de infraestructuras, en la localización de equipamientos, en la localización de vivienda pública y en la gentrificación de barrios a través de políticas de regeneración urbana, etc. Además, en los países con Estado del bienestar, también es el responsable de la efectividad de las políticas redistributivas de renta, las cuales tienen un efecto directo sobre la desigualdad social. En definitiva, según este planteamiento, el Estado incide en la configuración de las formas urbanas tanto de forma directa como indirecta ${ }^{14}$. En este sentido, el rol del Estado puede hacer aumentar las divisiones jerárquicas en la ciudades - como en el caso de Estados Unidos, donde su injerencia en la corrección de los efectos del mercado es prácticamente inexistente- o puede moderar la desigualdad social y, por lo tanto, reducir la intensidad de las dinámicas de segregación residencial socioeconómica -como en el caso de los países europeos, entre los que también se producen diferencias atendiendo a los diferentes modelos de Estado del bienestar ${ }^{15}-$.

11 Algunas de las críticas más importantes realizadas sobre el modelo de Ciudad Dual son las realizadas por Harloe y Fanstein (1992) o Hamnett (1994).

12 Castells y Mollenkopf, 1991.

13 Marcuse, 1993; Marcuse y van Kempen, 2000, 2002.

14 Musterd, 1994; Musterd y Ostendorf, 1998; Marcuse y van Kempen, 2002

15 Esping-Andersen, 1990; van der Wusten y Musterd, 1998. 
Marcuse, igual que Sassen, también considera que la desindustrialización y la globalización han reforzado las divisiones en la ciudad y han acentuado las desigualdades socioeconómicas entre la población urbana ${ }^{16}$, pero desde su punto de vista este proceso se refleja en el espacio urbano de una manera más compleja que la que se recoge en el modelo de ciudad dual. En este sentido, más que un simple aumento de la segregación residencial socioeconómica, Marcuse señala que en el contexto actual se están produciendo fenómenos como la gentrificación, la expansión de áreas donde reside población rica, el crecimiento y el empeoramiento de las condiciones de vida en los guetos o la reducción de los barrios de trabajadores industriales y de clase media. Todo ello implica más bien un aumento de la fragmentación urbana y una polarización de la estructura socio-residencial. Esta afirmación la hace entendiendo que las dinámicas de segregación residencial no son otra cosa que formas de confinamiento de un grupo social generadas por las dinámicas de localización residencial de otro grupo social con más poder. Su hipótesis es que en la ciudad cada grupo social sigue una estrategia residencial determinada. Así, la clase trabajadora se quiere separar de la población excluida, la clase media se quiere separar tanto de los excluidos como de la clase trabajadora, al mismo tiempo que los grandes empresarios y las clases altas también buscan su seguridad apartándose del resto. Este mecanismo basado en las aspiraciones residenciales de los grupos sociales, a veces contrapuestas, es el que da lugar a los procesos de fragmentación de la estructura socio-residencial, los cuales constituyen la base del modelo de ciudad cuarteada ${ }^{17}$.

Este planteamiento teórico, que a priori se ajusta mejor al contexto europeo ${ }^{18}$, es el que se busca contrastar en esta investigación con el análisis de cinco de las metrópolis más importantes de España: Madrid, Barcelona, Valencia, Bilbao y Sevilla. Los objetivos del estudio son dos principalmente: (a) constatar si en todas la metrópolis aumenta la fragmentación y la polarización de la estructura socio-residencial e (b) identificar qué factores se encuentran más asociados con este fenómeno, particularmente con la polarización socio-residencial. Respecto a la segunda cuestión, más allá de la globalización y la desindustrialización, que son los factores que desde el punto de vista teórico más relevancia se otorga desde el modelo de ciudad cuarteada, también se han analizado otros factores, como el tamaño de la población, la densidad poblacional o el impacto de la crisis. De esta manera, se han incorporado otros elementos explicativos que han aparecido en algunos de los estudios más recientes sobre el aumento de la desigualdad y de la segregación socioeconómica tanto en el contexto norteamericano ${ }^{19}$, como europeo ${ }^{20}$.

16 Marcuse, 1996.

17 Marcuse, 1993; Marcuse y van Kempen, 2000, 2002.

18 Como se ha explicado anteriormente, este modelo teórico considera la incidencia del Estado del bienestar como un aspecto central en la configuración de la estructura socio-residencial. Precisamente, éste es uno de sus principales rasgos distintivos respecto al modelo de ciudad dual, que se ajusta mejor a contextos de corte neoliberal con escasa participación del Estado en el mercado inmobiliario y en materia de protección social.

19 Florida, 2017.

20 Tammaru et al., 2016. 
Por lo tanto, las preguntas de investigación que se han planteado para estudiar la evolución de la estructura socio-residencial de la realidad urbana española son:

1. ¿Se identifica una tendencia de fragmentación y de polarización en los procesos de estructuración socio-residencial de las principales metrópolis españolas durante la última década?

2. La polarización de la estructura socio-residencial en las metrópolis españolas, ¿guarda alguna relación con el tamaño o la densidad de las metrópolis, con los procesos de desindustrialización y de globalización o con el impacto de la crisis?

Ante estas cuestiones y con base en la literatura revisada expuesta anteriormente, las hipótesis que se plantean de inicio son las siguientes:

1. La estructura socio-residencial de las metrópolis españolas ha tendido a fragmentarse y a polarizarse en los últimos años.

2. La polarización socio-residencial tiende a intensificarse cuando se dan las siguientes situaciones:

- El tamaño poblacional de la metrópolis es mayor.

- La densidad de la metrópolis es menor.

- La exposición a la globalización es mayor o cuando el grado de internacionalización de la metrópolis es más elevado.

- El proceso de desindustrialización está más avanzado.

- El impacto de la crisis ha sido más fuerte.

\section{Fuentes de datos y métodos de análisis Fuentes de datos}

Para llevar a cabo esta investigación se han utilizado dos fuentes de datos básicamente: el Censo de Población y Viviendas y los indicadores recopilados en el proyecto Urban Audit. El Censo de Población y Viviendas, desarrollado por el Instituto Nacional de Estadística (INE) cada 10 años, provee de información del total de la población (sexo, edad, lugar de nacimiento, nivel de estudios, relación con la actividad, categoría ocupacional, etc.), de los hogares (composición demográfica), los edificios (estado, número de plantas, etc.) y las viviendas (superficie, régimen de tenencia, etc.). La unidad territorial más pequeña sobre la que ofrece información es la sección censal ${ }^{21}$, por lo que es la fuente de información de referencia para realizar análisis socio-territoriales. En este caso se ha trabajado a esta escala a través de los porcentajes totales marginales por sección censal de cada una de las categorías de las variables utilizadas.

No obstante, como es sabido, la última edición del censo (2011) presenta déficits de información a esta escala territorial ${ }^{22}$. Para superar este hándicap y evitar perder

21 La sección censal es una unidad territorial inframunicipal que está delimitada preferentemente por límites fácilmente identificables (accidentes naturales, viales, etc.) y que aglutina una población de entre 1.000 y 2.500 residentes.

22 Para más información respecto a esta cuestión puede consultarse el contenido del seminario "Impacto de la metodología del nuevo censo 2011 en las investigaciones socio-urbanísticas" (Madrid, 26 de marzo y 3 de abril de 2014), organizado por el Departamento de Análisis Social de la Universidad Carlos III y por el Departamento de Urbanística y Ordenación del Territorio de la Universidad Politécnica de Madrid, en el siguiente enlace: http://www2.aq.upm.es/ 
detalle territorial de la información se ha optado por utilizar los datos resultantes de un tratamiento realizado por el equipo estadístico del Institut d'Estudis Regionals i Metropolitans de Barcelona (IERMB). Este tratamiento ha consistido en la imputación de la información faltante a través de un método de regresiones secuenciales multivariables ampliamente utilizado por oficinas estadísticas europeas para la imputación de la variable renta ${ }^{23}$.

Respecto a la información de Urban Audit, en primer lugar, hay que decir que ya para definir el ámbito territorial de las diferentes metrópolis que se analizan en este estudio se ha adoptado la delimitación de áreas urbanas funcionales (AUF) que se realiza en el marco de este proyecto europeo ${ }^{24}$. Esto, precisamente, ha facilitado el uso de diferentes indicadores disponibles para estos ámbitos metropolitanos, como el tamaño poblacional, la densidad, la proporción de población extranjera, la proporción de población ocupada en servicios o la tasa de desempleo. Este conjunto de informaciones se utilizan en la última fase del análisis para identificar los factores que guardan más relación con los procesos de polarización socio-residencial.

\section{Hacia una ecología factorial retroductiva}

La ecología factorial engloba un conjunto extenso de trabajos que tienen su auge en Estados Unidos en los años 60 y 70 y que se basan en el estudio de los ejes estructurantes del espacio urbano a partir del análisis factorial de datos censales ${ }^{25}$. Aunque el éxito de la ecología factorial como método de estudio de la estructura socio-residencial resulta innegable a la luz de su extensa aplicación en diferentes contextos urbanos, su uso comienza a decaer ya a finales de la década de los 70 como consecuencia de las críticas que recibe. El marcado carácter inductivo del método, que en su origen fue valorado como uno de sus puntos fuertes, es criticado duramente con el paso de los años ante la falta de base teórica para interpretar los resultados obtenidos. No obstante, continúa habiendo autores que defienden la utilidad de la ecología factorial como instrumento para el estudio de los patrones de cambio socio-residencial en las ciudades postindustriales ${ }^{26}$. Esta investigación se sitúa en esa línea, sirviéndose del marco que ofrece la ecología factorial para continuar experimentando y añadiendo innovaciones metodológicas que permitan conocer mejor las dinámicas urbanas de estructuración socio-residencial ${ }^{27}$.

Departamentos/Urbanismo/blogs/re-hab/impacto-de-la-metodologia-del-nuevo-censo-depoblacion-y-vivienda-2011-en-las-investigaciones-socio-urbanisticas/

23 Este método se implementa a través del software IVEware (Raghunathan et al. 2001). Una explicación más detallada de este método se puede encontrar en Porcel (2020).

24 El Urban Audit es un proyecto europeo creado en los años 90 con la finalidad de comparar la calidad de vida en las grandes ciudades europeas. La información es recogida y publicada en ciclos de 3 años por los institutos de estadística nacionales (en el caso de España, el INE). Para más información consultar la página web del Instituto Nacional de Estadística (www.ine.es)

25 Una revisión exhaustiva de esta corriente de análisis se puede consultar en Checa (2006).

26 Andersen, 1998; Hatz, 2009; Précteceille, 2004.

27 Últimamente se han diseñado metodologías más complejas que, para obtener una mayor precisión analítica, complementan el aporte del análisis factorial con otras técnicas de análisis. Por ejemplo, hay investigaciones en las que se encadena al análisis factorial un análisis de 
La aplicación de la ecología factorial es uno de los aspectos clave a nivel metodológico de esta investigación en la concreción de la estructura socio-residencial de cada una de las metrópolis analizadas. No obstante, para superar el enfoque meramente inductivo de la ecología factorial tradicional se ha adoptado una estrategia "retroductiva", a través de la cual se ha facilitado un diálogo entre las observaciones empíricas y la teoría con el objetivo de adquirir un conocimiento más preciso del fenómeno estudiado. La estrategia "retroductiva" parte de la premisa de que el conocimiento de las estructuras que integran la realidad social pasa por el examen de las observaciones empíricas y de su contraste con la teoría, realizando preguntas y abriendo nuevos espacios (si es necesario) a la resignificación y la conceptualización más allá de las asunciones previas ${ }^{28}$.

Esta lógica es la que ha guiado la aproximación que se ha llevado a cabo para la construcción de la tipología de áreas socio-residenciales en este estudio, aprovechando el potencial de los outputs empíricos de la ecología factorial y de las asunciones

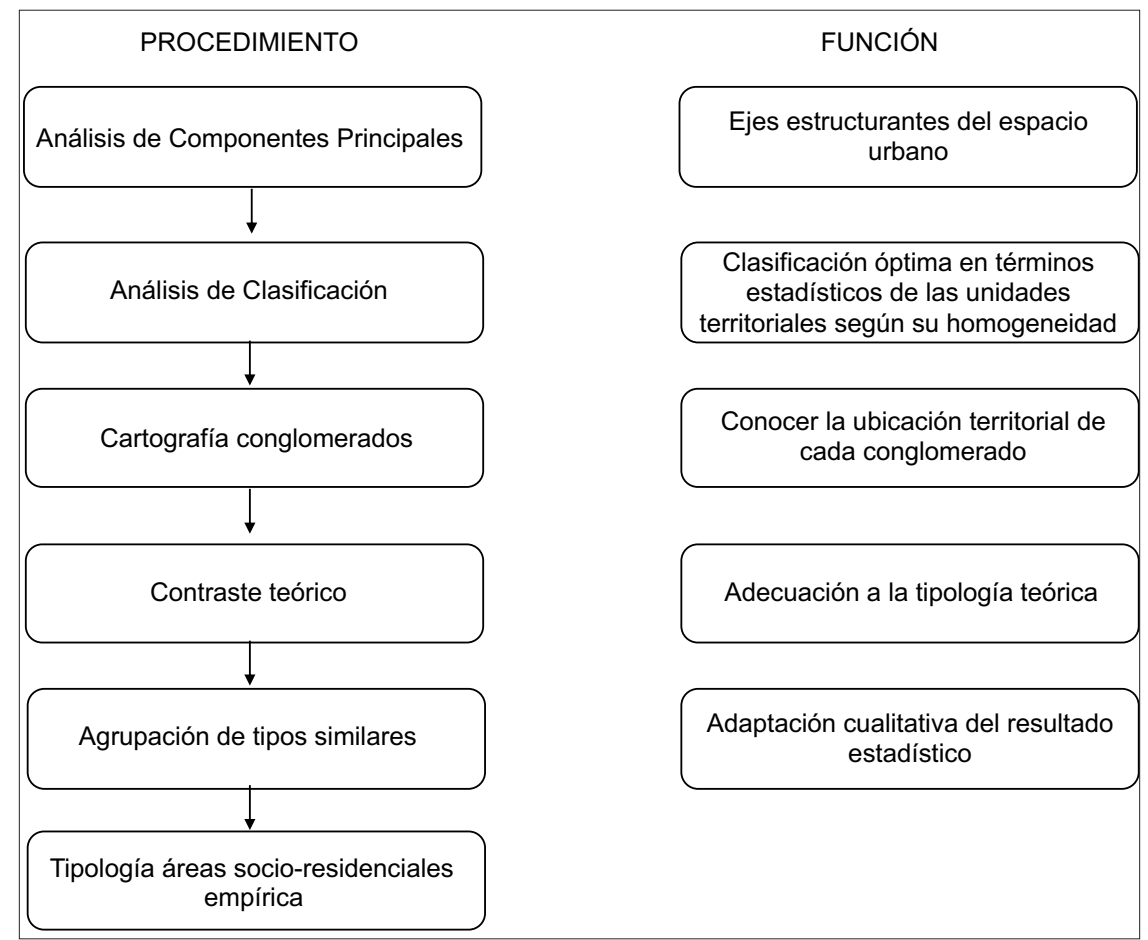

Gráfico 2. Procedimiento de ecología factorial retroductiva Fuente: elaboración propia

conglomerados, a lo que además se añade un análisis discriminante (Rodríguez, 2000) o se integran datos de encuesta (Lozares y Domínguez, 1993, 1996; Lozares et al. 2003; Costa y Porcel, 2013). En otras ocasiones también se han aplicado técnicas de análisis territorial, como el índice de Moran, a los ejes resultantes del análisis factorial (Pérez y Santos, 2011) o incluso se ha articulado un análisis de conglomerados con el análisis de información cualitativa (Duhau y Giglia, 2008), todo ello con el objetivo de ganar precisión analítica partiendo de la propuesta inicial de la ecología factorial.

28 Meyer y Lunnay, 2013. 
teóricas sobre áreas socio-residenciales de Marcuse ${ }^{29}$. El procedimiento que se ha seguido se estructura en cinco pasos (gráfico 2).

El primer paso consiste en la ejecución de un Análisis de Componentes Principales (ACP), con el objetivo de obtener los ejes estructurantes del espacio urbano más relevantes de cada metrópolis. Este análisis se realiza con información del Censo de Población y Viviendas a nivel de sección censal y las variables utilizadas han sido seleccionadas en función de su pertenencia a las diferentes dimensiones que se han preestablecido a nivel teórico como estructuradoras del espacio urbano. Estas dimensiones son: estatus social, estatus familiar, cultura/inmigración, estructura de la propiedad y morfología residencial (cuadro 3). Los análisis se han realizado de manera independiente en cada una de las metrópolis estudiadas (Madrid, Barcelona, Bilbao, Valencia, Sevilla) para los años 2001 i 2011.

Cuadro 3. Viariables censales utilizadas la secuencia de análisis $(A C P+A C L)$ para construir la tipología de áreas socio-residenciales.

\begin{tabular}{|c|c|c|}
\hline Dimensiones & Variables & Marginales \\
\hline \multirow[t]{13}{*}{ Estatus social } & $\begin{array}{l}\text { Categoría } \\
\text { socioprofesional }\end{array}$ & $\begin{array}{l}\text { \% de población ocupada en categorías } \\
\text { ocupacionales "altas" (1+2) (IND 11 A)) }\end{array}$ \\
\hline & & $\begin{array}{l}\text { \% de población ocupada en cateogrías } \\
\text { ocupacionales "medias" (3+4) (IND 11B) }\end{array}$ \\
\hline & & $\begin{array}{l}\text { \% de población ocupada en categorías } \\
\text { ocupacionales "bajas" }(0+5+6+7+8+9) \text { (IND } \\
\text { llc) }\end{array}$ \\
\hline & Sector de actividad & $\begin{array}{l}\text { \% de población ocupada: sector primario } \\
(\mathrm{A}+\mathrm{B})(\text { IND2A) }\end{array}$ \\
\hline & & $\begin{array}{l}\text { \% de población ocupada sector industrial y } \\
\text { construcción }(\mathrm{C}+\mathrm{D}+\mathrm{E}+\mathrm{F})(\text { IND2B) }\end{array}$ \\
\hline & & $\begin{array}{l}\text { \% de población ocupada sector servicios } \\
(\mathrm{G}+\mathrm{H}+\mathrm{I}+\mathrm{J}+\mathrm{K}+\mathrm{L}+\mathrm{M}+\mathrm{N}+\mathrm{O}+\mathrm{P}+ \\
\mathrm{Q}+\mathrm{R}+\mathrm{S}+\mathrm{T}+\mathrm{U})(\mathrm{IND} 2 \mathrm{C})\end{array}$ \\
\hline & $\begin{array}{l}\text { Relación con la } \\
\text { actividad }\end{array}$ & \% de población ocupada (IND4A) \\
\hline & & \% de población parada (IND4B) \\
\hline & & \% de población inactiva (IND4C) \\
\hline & Paro en el hogar & $\begin{array}{l}\text { \% hogares con todos sus miembros activos } \\
\text { parados (INDI0D) }\end{array}$ \\
\hline & $\begin{array}{l}\text { Nivel de estudios } \\
\text { acabados }\end{array}$ & $\begin{array}{l}\text { \% de población con estudios primarios o } \\
\text { inferiores (IND62A+B) }\end{array}$ \\
\hline & & $\begin{array}{l}\text { \% de población con estudios secundarios } \\
\text { (IND62C) }\end{array}$ \\
\hline & & $\begin{array}{l}\text { \% de población con estudios terciarios } \\
\text { (IND62D) }\end{array}$ \\
\hline
\end{tabular}

29 Marcuse, 1993. 


\begin{tabular}{|c|c|c|}
\hline \multirow[t]{13}{*}{ Curso vital } & Estructura del hogar & $\begin{array}{l}\text { \% de hogares unipersonales (IND9A) } \\
\% \text { de hogares monoparentales con hijos (con/ } \\
\text { sin otros miembros) (IND9B) }\end{array}$ \\
\hline & & $\begin{array}{l}\text { \% de hogares parejas sin hijios (con/sin } \\
\text { otros) (IND9C) }\end{array}$ \\
\hline & & $\begin{array}{l}\text { \% de hogares parejas con hijos (con/sin } \\
\text { otros) (IND9D) }\end{array}$ \\
\hline & & \% de hogares múltiples (IND9E) \\
\hline & & \% de hogares sin núcleo (IND9F) \\
\hline & Edad & \% de población de 0 a 14 años (IND72A) \\
\hline & & \% de población de 15 a 34 años (IND72B) \\
\hline & & \% de población de 35 a 64 años (IND72C) \\
\hline & & \% de población de 65 años y más (IND72D) \\
\hline & Tamaño del hogar & $\%$ de hogares de 1 miembro (IND8A) \\
\hline & & $\%$ de hogares de 2 miembros (IND8B) \\
\hline & & $\%$ de hogares de 3 miembros (IND8C) \\
\hline & & \% de hogares de 4 o más miembros (IND8D) \\
\hline \multirow[t]{8}{*}{ Origen geográfico } & Lugar de nacimiento & \% de población nacida en España (IND51A) \\
\hline & & $\begin{array}{l}\text { \% de población nacida fuera de España } \\
\text { (IND51B) }\end{array}$ \\
\hline & $\begin{array}{l}\text { Año de llegada a la } \\
\text { vivienda }\end{array}$ & $\begin{array}{l}\text { \% de población llegada a la vivienda hace } \\
\text { más de } 10 \text { años o no ha cambiado (INDl11A) }\end{array}$ \\
\hline & & $\begin{array}{l}\text { \% de población llegada a la vivienda hace } \\
\text { menos de } 10 \text { años (INDl11B) }\end{array}$ \\
\hline & $\begin{array}{l}\text { Año de llegada a } \\
\text { España }\end{array}$ & $\begin{array}{l}\% \text { de población llegada a España hace más de } \\
10 \text { años (IND13B) }\end{array}$ \\
\hline & & $\begin{array}{l}\text { \% de población llegada a España hace menos } \\
\text { de } 10 \text { años (IND13B) }\end{array}$ \\
\hline & $\begin{array}{l}\text { Año de llegada al } \\
\text { municipio }\end{array}$ & $\begin{array}{l}\% \text { de población llegada al municipio hace } \\
\text { más de } 10 \text { años (IND121A) }\end{array}$ \\
\hline & & $\begin{array}{l}\text { \% de población llegada al municipio hace } \\
\text { menos de } 10 \text { años (IND121B) }\end{array}$ \\
\hline \multirow[t]{4}{*}{$\begin{array}{l}\text { Tenencia de la } \\
\text { vivienda }\end{array}$} & Régimen de tenencia & $\begin{array}{l}\text { \% de hogares con vivienda en propiedad } \\
\text { totalmente pagada (IND15A) }\end{array}$ \\
\hline & & $\begin{array}{l}\% \text { de hogares con vivienda en propiedad con } \\
\text { pagos pendientes (IND15B) }\end{array}$ \\
\hline & & $\begin{array}{l}\text { \% de hogares con vivienda de alquiler } \\
\text { (IND15C) }\end{array}$ \\
\hline & & $\begin{array}{l}\text { \% de hogares con vivienda en otros tipos de } \\
\text { regímenes de tenencia (INDI5D) }\end{array}$ \\
\hline
\end{tabular}




\begin{tabular}{lll}
\hline Morfología urbana & $\begin{array}{l}\text { Superficie de la } \\
\text { vivienda }\end{array}$ & $\begin{array}{l}\text { \% de hogares con vivienda de superficie: } \\
\text { hasta } 75 \mathrm{~m}^{2} \text { (IND3B) }\end{array}$ \\
& $\%$ de hogares con vivienda de superficie: $76-$ \\
& $120 \mathrm{~m}^{2}$ (IND3B) \\
& $\%$ de hogares con vivienda de superficie: más \\
& de $120 \mathrm{~m}^{2}$ (IND3C) \\
\cline { 2 - 3 } & \% de edificios en estado ruinoso, malo o \\
conservación & deficiente (INDl6A) \\
& \% de edificios en estado bueno (INDl6B) \\
\hline
\end{tabular}

Fuente: elaboración propia.

A partir de los resultados de este análisis factorial se ha realizado un Análisis de Clasificación (ACL) con el objetivo de agrupar con criterios estadísticos las secciones censales más homogéneas (conglomerados). La idea fundamental en este paso es conseguir una primera tipología de áreas socio-residenciales detallada, óptima en términos estadísticos, que cumple básicamente con dos funciones. Por un lado, el planteamiento inductivo en esta fase del análisis permite hacer emerger las especificidades de la estructura socio-residencial de cada contexto urbano. Por otro lado, esta primera tipología permite reducir la información para abordar el trabajo cualitativo en la siguiente fase, consistente en el contraste teórico. Otro elemento que ayuda al contraste teórico es la cartografía de esta primera tipología estadística, la cual aporta más información para interpretar el carácter de cada conglomerado.

Una vez se dispone de una primera clasificación de las secciones censales y de su cartografía se procede a contrastar los resultados con la tipología teórica de áreas socio-residenciales de Marcuse (Marcuse, 1993), la cual se ha adoptado como referencia. Los diferentes tipos teóricos que reconoce este autor en la estructura socio-residencial de las ciudades globalizadas son:áreas lujosas (Luxury Housing), áreas gentrificadas (Gentrified City), áreas suburbanas (Suburban City), enclaves étnicos (Ethnic Encalve), áreas degradadas (Abandoned City) y áreas urbanas comunes, que albergan clases intermedias y trabajadoras (Tenement City). En este procedimiento estos tipos teóricos adquieren un papel de tipos ideales y se trata de asociarlos con los conglomerados resultantes del ACL anterior. Este análisis comporta la agrupación de diferentes conglomerados, realizada ya no por criterios estadísticos, sino como resultado del análisis cualitativo del conjunto de información disponible.

De esta manera se configura la tipología de áreas socio-residenciales empírica definitiva. En el cuadro siguiente (4) se recoge la correspondencia de los tipos teóricos y empíricos de áreas socio-residenciales según los años en que han aparecido con un breve descriptor de cada una de ellas. Más adelante, en los apartados de análisis, se muestran la presencia de cada uno de estos tipos de áreas socio-residenciales en las diferentes metrópolis analizadas.

Es importante también destacar que el único tipo teórico de áreas socio-residenciales que no tiene correspondencia empírica en las diferentes metrópolis españolas estudiadas es el enclave étnico (Ethnic Enclave). Es preciso tener en cuenta 
que cuando Marcuse ${ }^{30}$ habla de enclave étnico se refiere más bien a la idea de "comunidades urbanas"31, compuestas en una proporción muy elevada por población de un mismo origen cultural o de una misma etnia diferente a la mayoritaria, que mantiene prácticas culturales y de consumo propias, relacionadas con su lugar de origen, y que no necesariamente presentan un perfil socialmente vulnerable. Tal y como expresan los resultados, empíricamente no se han detectado áreas de estas características con un peso relevante en la estructura socio-residencial de las metrópolis estudiadas. Esto es congruente, además, con lo que apuntan algunos estudios que se han centrado en esta materia en el caso de Barcelona, por ejemplo ${ }^{32}$. Por otro lado, esto no quiere decir que en las últimas décadas no se hayan producido pautas de concentración residencial de la población extranjera o procedentes de un país concreto. No obstante, por lo que muestran los datos, de momento se trata de áreas residenciales muy diversas en cuanto a los orígenes de los residentes y habitualmente vinculadas a elementos de vulnerabilidad urbana, por lo que mayoritariamente han quedado englobadas como áreas degradadas. Sobre esta cuestión vale la pena apuntar también que los enclaves étnicos que aparecen con más claridad en las urbes españolas son los conformados por población de etnia gitana. En este caso, sin embargo, resulta imposible hacerlos aflorar empíricamente con la información disponible en el Censo de Población y Viviendas, ya que no se dispone de ninguna variable que permita identificar la etnia gitana. Esto, por lo tanto, sí que constituye una limitación importante del análisis que se ha desarrollado.

Cuadro 4. Tipos de áreas socio-residenciales. Metrópolis españolas, 2001-2011

Tipología de áreas socioresidenciales teórica

(Marcuse, 1993;

Marcuse i Van

Kempen, 2000)

Luxury Housing

Suburban City

Áreas suburbanas
Áreas gentrificadas

Tipos resultantes

Áreas residenciales de clases medias y altas

Tipología de áreas socioresidenciales resultante

2011

2001-2011

Años
(presencia)

2001-2011
Profesionales directivos, formación superior, hogares con o sin hijos, viviendas de superficie elevada y en buen estado.

Profesionales y directivos, formación superior, población extranjera, hogares unipersonales, sin núcleo o sin ijos, vivienda de pequeña superficie de alquiler.

Hogares en expansión de llegada reciente a la vivienda y al municipio. Vivienda de superficie media-alta y de propiedad con pagos pendientes.

30 Marcuse, 1993.

31 Gans, 1962; Suttles, 1968.

32 Martori y Aparicio, 2011; Galeano et al., 2014. 


\begin{tabular}{lcc}
\hline Tenement City & $\begin{array}{l}\text { Áreas residenciales } \\
\text { de clases intermedias }\end{array}$ & Trabajadores de servicios \\
y trabajadoras & cualificados y semi-cualificados, y \\
& trabajadores de la construcción o \\
& de la industria, poco cualificados \\
& con niveles de formación bajos. \\
& Autóctonos, residentes en viviendas \\
de superficie media o reducida en & propiedad sin pagos pendientes. \\
& Situaciones de paro, aunque no \\
& muy predominantes y en algunas \\
& ocasiones presencia de extranjeros.
\end{tabular}

Ethnic Enclave

Abandoned City Áreas degradadas 2001-2011

Población envejecida y extranjera, hogares unipersonales y sin núcleo.

Trabajadores de servicios no cualificados y situaciones de paro. Viviendas de superficie reducida y mal estado de los edificios

Fuente: elaboración propia.

Por último, en cuanto a los fenómenos que constituyen los ejes centrales de este estudio - fragmentación y polarización socio-residencial-, su operativización se ha realizado acorde con los planteamientos de Marcuse ${ }^{33}$. Por un lado, se considera que se produce fragmentación socio-residencial cuando aumentan los tipos de áreas socio-residenciales que conforman la estructura de las metrópolis analizadas. Por otro lado, se considera que se produce polarización socio-residencial cuando se detecta que hay un aumento de la proporción del espacio urbano ocupado por les áreas residenciales que reflejan más la desigualdad urbana, como áreas residenciales de lujo (Luxury Housing), áreas gentrificadas (Gentrified City), áreas suburbanas (Suburban City), enclaves étnicos (Ethnic Encalve) y áreas degradadas (Abandoned City). Todo ello iría en detrimento de las áreas urbanas tradicionalmente más comunes, que albergan mayoritariamente a las clases intermedias y trabajadoras (Tenement City) ${ }^{34}$.

\section{La estructura del espacio urbano en España}

En España los estudios sobre la estructura del espacio urbana realizados a través de la ecología factorial empiezan a realizarse con un cierto retraso. La década de los 80 es el periodo en el que proliferan más este tipo de investigaciones, aunque ya en los años 70 se realizaron algunos estudios próximos a esta línea ${ }^{35}$. Desde un punto de

33 Marcuse, 1993.

34 Marcuse y van Kempen 2000, 2002.

35 Entre ellas se puede destacar por su carácter pionero el estudio que realiza Manuel de SolàMorales (1970) sobre un fragmento del área metropolitana de Barcelona, concretamente sobre lo que él denomina el área del Besòs (Badalona y su entorno). En esta investigación el autor desarrolla además un enfoque inédito hasta entonces, centrado en analizar la relación existente entre los ejes que estructuran el territorio desde el punto de vista morfológico y urbanístico y los ejes que estructuran la población residente en esa área urbana. 
vista más ortodoxo son objeto de este tipo de análisis las ciudades de Madrid ${ }^{36}$, Barcelona $^{37}$, Granada ${ }^{38}$, Alcalá de Henares ${ }^{39}$, Málaga ${ }^{40}$, Bilbao ${ }^{41}$ o Sevilla ${ }^{42}$. Pese a la heterogeneidad de las variables incorporadas en los análisis factoriales en estos estudios y las limitaciones que ello conlleva para realizar una mirada comparativa, $M^{a}$ Ángeles Díaz sintetiza a grandes rasgos las particularidades de la estructura socio-residencial de las ciudades españolas en los primeros años de democracia a partir de gran parte de estos estudios ${ }^{43}$.

Según Díaz, a diferencia de las ciudades norteamericanas o europeas, en las ciudades españolas el estatus socioeconómico no es siempre el eje estructurante del espacio urbano más relevante, aunque evidentemente su peso es importante. Por otro lado, el comportamiento del eje migratorio es diverso y complejo, sobre todo en su relación con el estatus social, ya que no en todas las ciudades estudiadas correlacionan en el mismo sentido. Si bien en ciudades industriales como Barcelona la población inmigrada aparece muy asociada a un estatus social bajo ${ }^{44}$, no ocurre lo mismo en algunas ciudades andaluzas de perfil turístico como, por ejemplo, Granada ${ }^{45}$, donde la relación es justo la contraria. Por último, otro aspecto particular de las ciudades españolas, pero que también se refleja en algunas ciudades europeas, es que el ciclo vital emerge como un elemento estructurante del espacio urbano de cierta relevancia. Predominantemente, las zonas urbanas centrales tienden a ser habitadas por población envejecida, mientras que en las zonas más periféricas hay una mayor presencia de población joven.

En el cuadro 5 se recoge una síntesis de los resultados de los ACP de las diferentes metrópolis analizadas en el contexto de esta investigación para los años 2001 y 2011. A pesar de que estos resultados no se han analizado en profundidad en este estudio, ya que se han utilizado como un medio en la construcción de la tipología de áreas socio-residenciales, sí que se pueden destacar algunos aspectos de interés respecto a las dinámicas de estructuración del espacio urbano en las metrópolis analizadas. En primer lugar, los ejes estructurantes más relevantes en todos los casos son los clásicos de las ciudades españolas: estatus social, curso vital y origen geográfico ${ }^{46}$. Además, se confirma de nuevo que el estatus social no es el factor estructurante más relevante ${ }^{47}$. Entre 2001 i 2011 lo que se observa es que, en general, el factor que más

36 Abrahamson y Johnson, 1974; del Campo, 1983; Jiménez-Blasco, 1984.

37 Ferras, 1977.

38 Fernández, 1978.

39 Díaz, 1986.

40 Ocaña, 1988.

41 Aurtenetxe, 1989.

42 Basulto y Arias, 1989.

43 Díaz, 1989.

44 Solà-Morales, 1970; Ferras, 1977.

45 Fernández, 1978.

46 Díaz, 1989.

47 Este fenómeno podría estar relacionado con la escala territorial del análisis. En este caso, las áreas funcionales, que engloban un territorio amplio. En otras investigaciones en las que se ha adoptado la misma metodología (y variables) para ámbitos más pequeños, como el territorio 
estructura la localización residencial de la población urbana española es el curso vital -centros envejecidos frente a periferias jóvenes-, aunque en 2011 el origen geográfico gana bastante peso en Madrid, Barcelona y Bilbao, seguramente como resultado del intenso proceso migratorio internacional que se produce con el cambio de siglo. Otro aspecto destacable es el aumento de la complejidad urbana, reflejada en la disminución generalizada de la variabilidad explicada en todos los casos de estudio. Es decir que la estructuración residencial de las metrópolis españolas se explica en gran medida por estos tres factores clásicos (estatus social, curso vital y origen geográfico), pero cada vez menos.

Cuadro 5. Factores estructurantes del espacio urbano (Análisis de Componentes Principales). Metrópolis españolas, 2001-2011

\begin{tabular}{|c|c|c|c|c|c|c|c|c|c|c|}
\hline \multirow{2}{*}{ Factores } & \multicolumn{2}{|c|}{ Barcelona } & \multicolumn{2}{|c|}{ Bilbao } & \multicolumn{2}{|c|}{ Madrid } & \multicolumn{2}{|c|}{ Sevilla } & \multicolumn{2}{|c|}{ Valencia } \\
\hline & 2001 & 2011 & 2001 & 2011 & 2001 & 2011 & 2001 & 2011 & 2001 & 2011 \\
\hline $\begin{array}{l}\text { Estatus Social } \\
\text { (clases sociales } \\
\text { altas vs clases } \\
\text { sociales bajas) }\end{array}$ & $\begin{array}{c}\text { Factor } 3 \\
(13,5 \%)\end{array}$ & $\begin{array}{c}\text { Factor } 3 \\
(11,6 \%)\end{array}$ & $\begin{array}{c}\text { Factor } 1 \\
(21,7 \%)\end{array}$ & $\begin{array}{l}\text { Factor 2 } \\
(13,3 \%)\end{array}$ & $\begin{array}{c}\text { Factor } 3 \\
(14,9 \%)\end{array}$ & $\begin{array}{c}\text { Factor } 3 \\
(10,9 \%)\end{array}$ & $\begin{array}{c}\text { Factor } 2 \\
(18,6 \%)\end{array}$ & $\begin{array}{c}\text { Factor } 2 \\
(15,7 \%)\end{array}$ & $\begin{array}{c}\text { Factor } 3 \\
(13,6 \%)\end{array}$ & $\begin{array}{l}\text { Factor } 3 \\
(10,7 \%)\end{array}$ \\
\hline $\begin{array}{l}\text { Curso vital } \\
\text { (población } \\
\text { envejecida vs } \\
\text { hogares en fase } \\
\text { expansiva) }\end{array}$ & $\begin{array}{c}\text { Factor 1 } \\
(25,9 \%)\end{array}$ & $\begin{array}{c}\text { Factor } 2 \\
(13,9 \%)\end{array}$ & $\begin{array}{c}\text { Factor } 2 \\
(18,7 \%)\end{array}$ & $\begin{array}{l}\text { Factor } 3 \\
(10,4 \%)\end{array}$ & $\begin{array}{c}\text { Factor } 1 \\
(24,6 \%)\end{array}$ & $\begin{array}{c}\text { Factor } 2 \\
(15,2 \%)\end{array}$ & $\begin{array}{c}\text { Factor } 1 \\
(22,7 \%)\end{array}$ & $\begin{array}{c}\text { Factor } 1 \\
(13,8 \%)\end{array}$ & $\begin{array}{c}\text { Factor } 1 \\
(25,4 \%)\end{array}$ & $\begin{array}{c}\text { Factor 1 } \\
(16,4 \%)\end{array}$ \\
\hline $\begin{array}{l}\text { Origen } \\
\text { geográfico/ } \\
\text { Grado de } \\
\text { arraigo en } \\
\text { el lugar de } \\
\text { residencia } \\
\text { (población } \\
\text { autóctona/ } \\
\text { Arraigo vs } \\
\text { población } \\
\text { extranjera/poco } \\
\text { arraigo) }\end{array}$ & $\begin{array}{c}\text { Factor } 2 \\
(16,5 \%)\end{array}$ & $\begin{array}{c}\text { Factor 1 } \\
(17,3 \%)\end{array}$ & $\begin{array}{c}\text { Factor } 3 \\
(14,0 \%)\end{array}$ & $\begin{array}{c}\text { Factor 1 } \\
(16,6 \%)\end{array}$ & $\begin{array}{c}\text { Factor } 2 \\
(16,5 \%)\end{array}$ & $\begin{array}{c}\text { Factor } 1 \\
(17,3 \%)\end{array}$ & $\begin{array}{c}\text { Factor } 3 \\
(12,5 \%)\end{array}$ & $\begin{array}{c}\text { Factor } 3 \\
(12,4 \%)\end{array}$ & $\begin{array}{c}\text { Factor } 2 \\
(15,8 \%)\end{array}$ & $\begin{array}{l}\text { Factor } 2 \\
(13,3 \%)\end{array}$ \\
\hline $\begin{array}{l}\text { Total } \\
\text { variabilidad } \\
\text { explicada }\end{array}$ & $55,9 \%$ & $42,7 \%$ & $54,4 \%$ & $40,3 \%$ & $56,0 \%$ & $43,3 \%$ & $53,7 \%$ & $41,4 \%$ & $54,9 \%$ & $40,4 \%$ \\
\hline
\end{tabular}

Fuente: elaboración propia a partir de INE, Censo de población y vivienda, 2001-2011.

\section{Fragmentación y polarización socio-residencial en las principales me- trópolis españolas}

Dos procesos caracterizan la evolución de las metrópolis españolas estudiadas en lo que se refiere a su composición socio-residencial. Un primer fenómeno hace referencia a la fragmentación de la estructura socio-residencial, es decir, a la aparición

vinculado al Área Metropolitana de Barcelona institucional (36 municipios), los resultados sí que reconocen un poder estructurante del estatus socioeconómico mucho más importante (Porcel, 2020). 
de nuevas áreas socio-residenciales. De los cuatro tipos identificados en 2001 se pasa a cinco en 2011 (gráfico 6). Es la irrupción de las denominadas áreas gentrificadas las que introducen diversidad en los ámbitos metropolitanos españoles. Si bien no pueden considerarse en sentido estricto áreas gentrificadas, el denominador común de estos espacios es la presencia predominante de las nuevas clases medias urbanas $^{48}$. Se trata de un nuevo perfil social urbano, caracterizado por una elevada formación y cualificación ocupacional, así como por un cierto carácter internacional debido al elevado peso que adquiere la población extranjera entre sus integrantes. No obstante, esta mayor fragmentación de la estructura socio-residencial no ha sido generalizada, estando presente sólo en tres de las metrópolis analizadas: Barcelona,

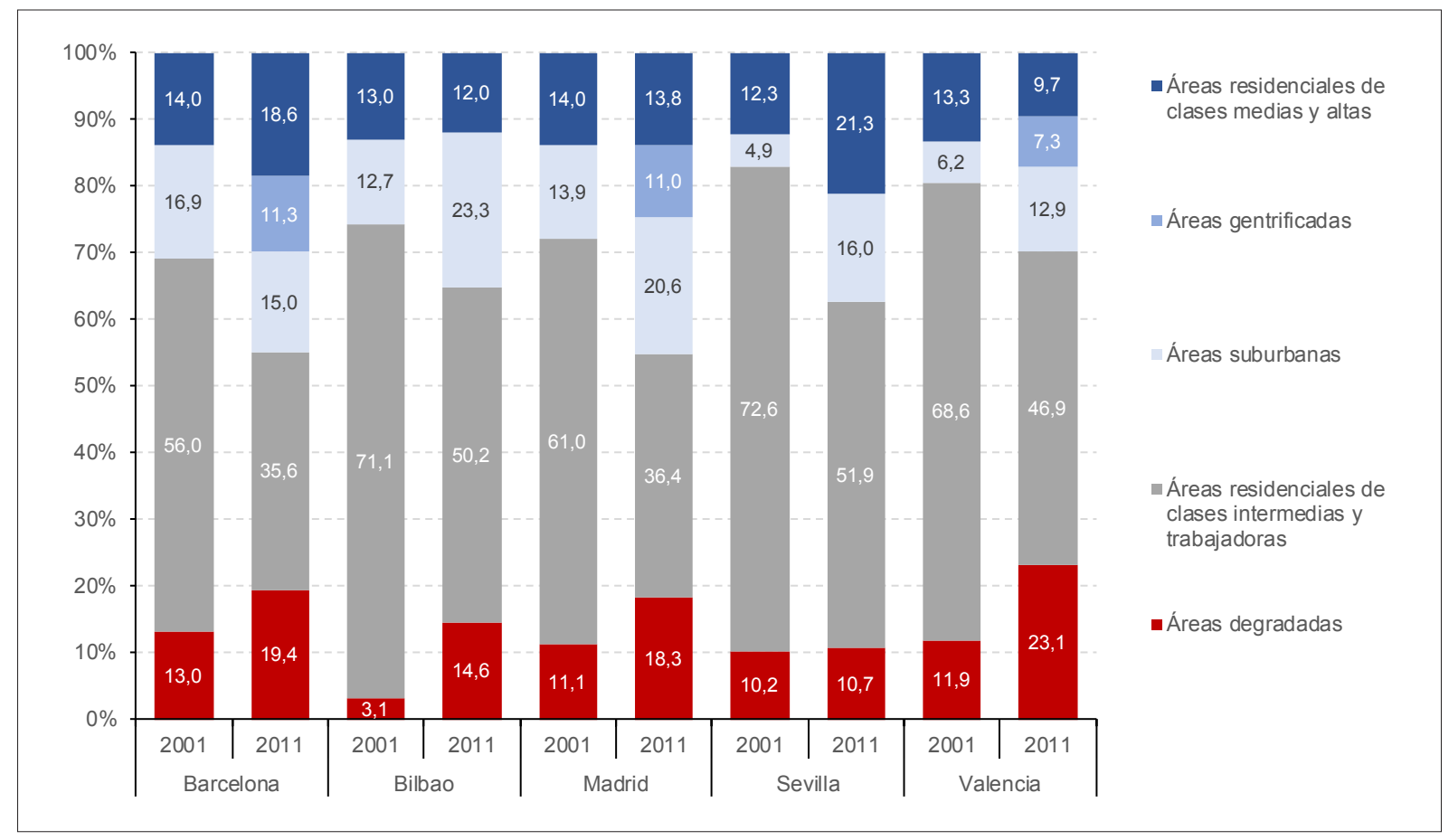

Gráfico 6. Espacio urbano según tipos de áreas socio-residenciales (\% de secciones censales). Metrópolis españolas, 2001-2011

Fuente: elaboración propia a partir de INE, Censo de población y viviendas, 2001-2011.

Madrid y Valencia. En este sentido, es importante apuntar el grado de integración de estas metrópolis en les dinámicas globales, especialmente Madrid y Barcelona ${ }^{49}$. En las metrópolis de Bilbao y Sevilla, en cambio, estos perfiles no tienen un peso significativo en el conjunto de la estructura urbana. Como tampoco lo tiene el alquiler, otro de los componentes claramente definitorios de las áreas gentrificadas ${ }^{50}$.

48 Un análisis más específico sobre este fenómeno en el contexto español se puede consultar en Sorando y Ardura (2016).

49 La clasificación de ciudades generadas por la Globalization and World Cities Research Network a partir del nivel de integración en la red de ciudades globales según la intensidad de flujos y producción en servicios avanzados sitúa Madrid y Barcelona entre las 50 primeras ciudades. Valencia, Bilbao y Sevilla, por este orden, también forman parte de esta clasificación, pero ocupando posiciones relegadas (https://www.lboro.ac.uk/gawc/gawcworlds.html).

50 Ver anexo estadístico. 
A la fragmentación se une el proceso de polarización socio-residencial de las metrópolis españolas, este sí generalizado. En el gráfico 7, se pude observar como en todas las metrópolis analizadas ha aumentado entre 2001 y 2011 el espacio ocupado por las áreas residenciales de clases medias y altas, las áreas gentrificadas y las áreas suburbanas, todas ellas favorecidas por la transición industrial-postindustrial. Simultáneamente, en el extremo inferior de la estructura urbana, el peso de las áreas degradadas también ha crecido en las metrópolis españolas (a excepción de Sevilla, donde se mantienen constantes), un fenómeno también asociado a los efectos de la globalización y la desindustrialización según la teoría. Sin embargo, las áreas residenciales de clases intermedias y trabajadores, las más amplias en términos espaciales y ubicadas en una posición intermedia del espectro socio-residencial, han perdido peso en todos los ámbitos metropolitanos.

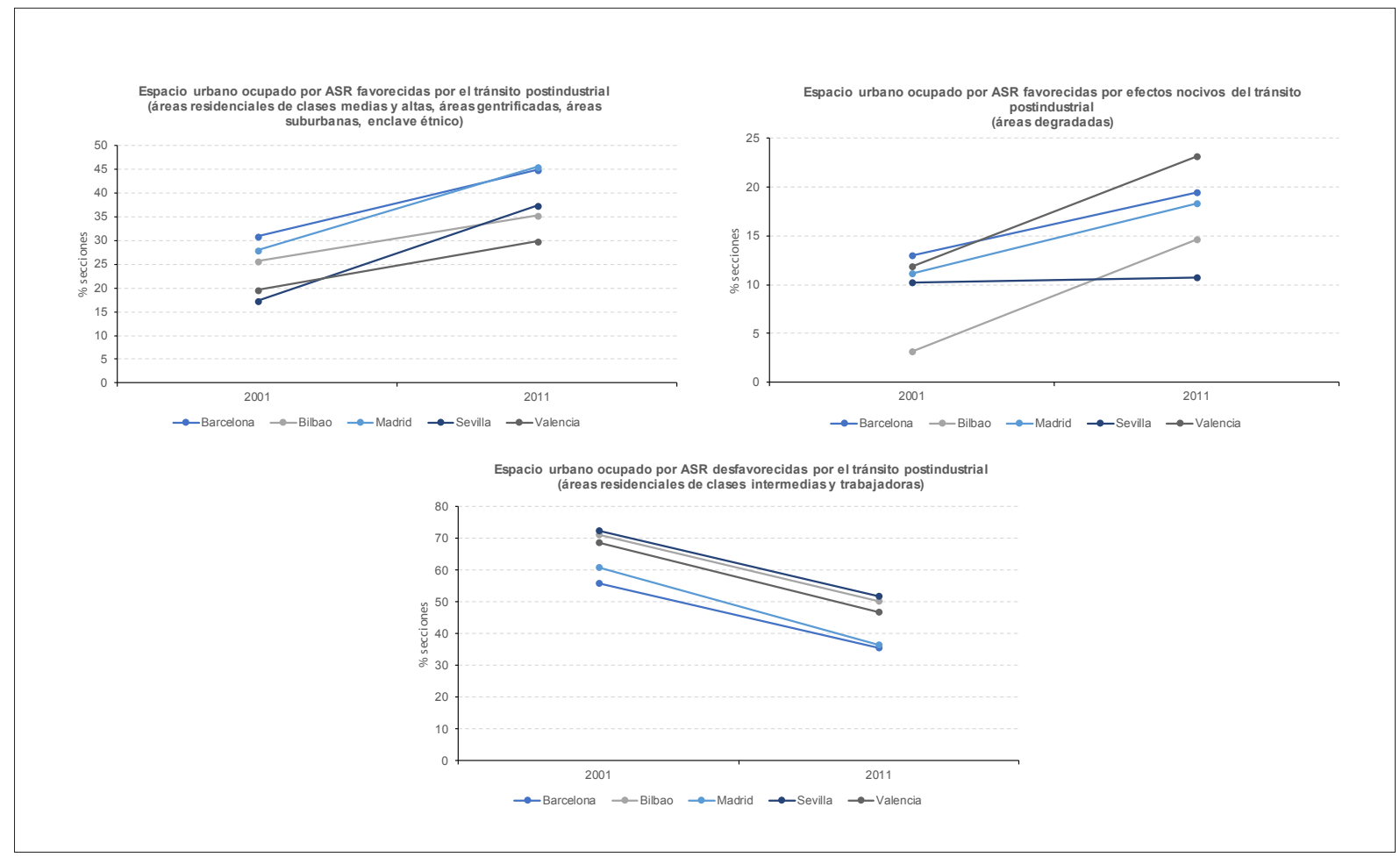

Gráfico 7. Evolución de la estructura socio-residencial según efectos del tránsito postindustrial (\% de secciones). Metrópolis españolas, 2001-2011

Fuente: elaboración propia a partir de INE, Censo de población y viviendas, 2001-2011.

Estos resultados corroboran, al menos parcialmente, la hipótesis propuesta de una doble tendencia de fragmentación y polarización socio-residencial de las metrópolis españolas. Si bien el proceso de polarización socio-residencial es reconocible en las cinco metrópolis estudiadas, la tendencia hacia una mayor fragmentación del espacio urbano no es generalizada. Bilbao y Sevilla, constituyen las excepciones respecto a este fenómeno. A pesar de ello, la evolución socio-residencial de las metrópolis estudiadas estarían en línea con el modelo de ciudad cuarteada ${ }^{51}$, ya que en ningún caso las metrópolis pierden diversidad.

51 Marcuse, 1993; Marcuse y van Kempen, 2000, 2002. 


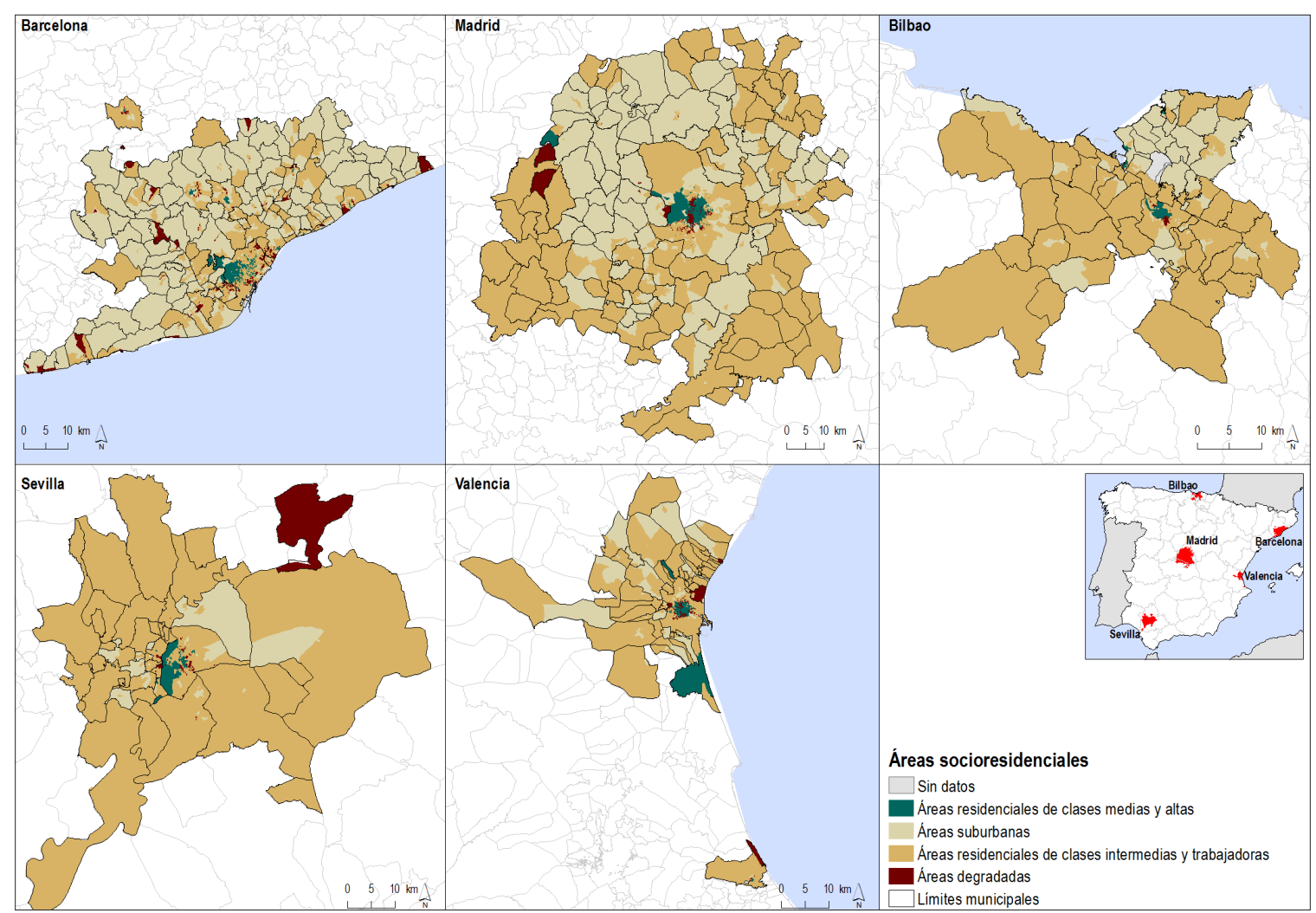

Mapa 1. Estructura socio-residencial. Metrópolis españolas, 2001

Fuente: elaboración propia a partir de INE, Censo de población y viviendas, 2001-2011.

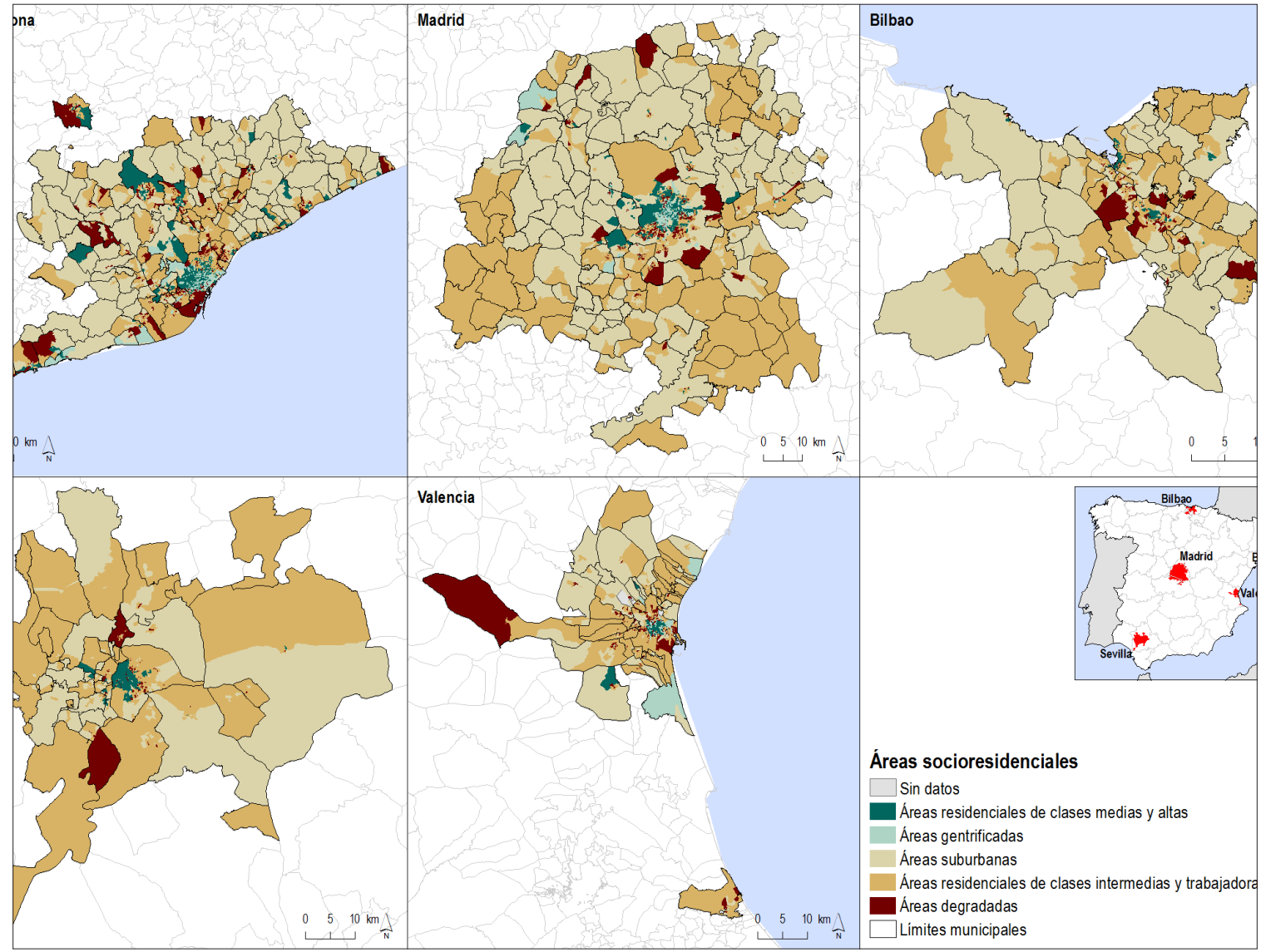

Mapa 2. Estructura socio-residencial. Metrópolis españolas, 2011

Fuente: elaboración propia a partir de INE, Censo de población y viviendas, 2001-2011. 
Un análisis más detallado de la evolución de las áreas socio-residenciales se puede realizar a partir de los mapas confeccionados para las cinco metrópolis y en los dos años estudiados. Los respectivos mapas permiten ver la localización de las respectivas áreas socio-residenciales en los cinco ámbitos metropolitanos y ver cómo ha variado su localización. De la lectura de los mapas 1 y 2 se pueden extraer diversas conclusiones.

Una primera idea clave es el proceso de (re)apropiación de los centros metropolitanos por parte de las clases medias y altas. En todas las metrópolis estudiadas, el centro se ha convertido en un espacio urbano en el que las clases medias son claramente mayoritarias, pero además se han extendido por gran parte del territorio del municipio central. Esta tendencia generalizada tiene matices en cada una de las metrópolis. Así, Barcelona, Madrid y Valencia han visto crecer en sus centros las áreas de nuevas clases medias, extendiéndose tanto éstas como las de clases medias tradicionales por el núcleo metropolitano. Bilbao y Sevilla, por otra parte, sin presencia de áreas de nuevas clases medias, han tendido a consolidar parte de sus áreas de clases medias y altas, un fenómeno muy marcado en el caso hispalense.

Los mapas permiten observar las particularidades territoriales de este fenómeno de las cinco metrópolis. En el caso de Madrid, las nuevas clases medias han acaparado los barrios del distrito Centro y se han extendido por numerosos barrios de la almendra central, sobre todo por el eje noreste, en algunos de los bastiones de las clases medias y altas tradicionales: barrios de los distritos de Retiro, Salamanca, Chamartín, o Chamberí. Ahora bien, los dos tipos socio-residenciales de clases medias también se han filtrado por áreas de asentamiento de clases intermedias y trabajadoras donde antes eran inexistentes o irrelevantes, como en barrios de los distritos de Tetuán, Hortaleza, San Blas, Moratalaz, Arganzuela o Carabanchel. En Barcelona, por su parte, la extensión ha sido también considerable, pero su filtración por los barrios vulnerables del norte es prácticamente inexistente, a diferencia de la porosidad vista en áreas vulnerables periféricas del municipio de Madrid. La elitización del centro metropolitano abarca gran parte de los barrios históricos del distrito de Ciutat Vella y se extiende por l'Eixample, los barrios del litoral y por los barrios periféricos de los distritos de Horta-Guinardó y Sant Andreu. En el caso de Valencia se produce una pérdida de áreas de clases medias y altas tradicionales en favor de áreas de nuevas clases medias. La proliferación de estas áreas ha tenido lugar en el distrito de Ciutat Vella, en los barrios de expansión del casco antiguo, en los distritos de l'Eixample y Extramurs, y en el este, en los barrios de los distritos de El Pla del Real, Algirós o Camins del Grau, filtrándose también por los poblados marítimos. Sevilla, por su parte, se caracteriza por la homogeneización del centro metropolitano debido a un crecimiento importante de las áreas de clases medias y altas tradicionales, en detrimento de las áreas mixtas que ocupaban amplios espacios en el municipio de Sevilla. Y en el caso de Bilbao se podría hablar de una evolución un tanto particular, en la medida que las áreas de clases medias y altas tradicionales pierden peso en favor de las áreas mixtas de clases intermedias y trabajadoras. Este 
fenómeno podría estar asociado, entre otros factores, por la localización de contingentes de población extranjera de bajo estatus socioeconómico en la confluencia de los distritos de Abando y Rekalde, entre los barrios de Indautxu y Abando del primer, y Ametzola y Iralabarri del segundo.

Un segundo proceso relevante ha sido la dispersión de las clases medias por espacios diversos de la periferia metropolitana. A pesar de su consolidación y expansión por los centros metropolitanos, la difusión de las áreas de clases medias por el territorio va incluso más allá de las lindes de los municipios centrales. La aparición de estos espacios va ligada en gran parte a la evolución de áreas suburbanas ${ }^{52}$. En la metrópolis de Barcelona, donde más peso tienen las clases medias, tradicionales y nuevas, la configuración de un sistema urbano policéntrico ha favorecido la aparición y asentamiento de las clases medias en ámbitos urbanos más allá de la ciudad central. Los centros urbanos y ensanches de numerosas ciudades de la primera y segunda corona, pero también sus respectivos ámbitos periféricos, han visto proliferar enclaves tanto de clases medias y altas tradicionales como de nuevas clases medias. Es el caso de Badalona, Cerdanyola del Vallès, Esplugues de Llobregat, Sant Just Desvern, Cerdanyola del Vallès, Gavà o Castelldefels en la primera corona, o Sabadell, Terrassa, Mataró, Sitges o Vilanova i la Geltrú. En el caso de Madrid, esta dispersión tiene lugar en un territorio más restringido, fundamentalmente a partir de un eje que va de norte a sur al oeste del municipio de Madrid, donde se han producido en los últimos años nuevos desarrollos orientados a perfiles poblacionales de estatus socioeconómico alto. Esta área integraría los municipios de las Rozas y Majadahonda, pasando por Pozuelo de Alarcón y hasta Bobadilla del Monte y Villaviciosa de Odón. Las periferias de las tres metrópolis restantes, en cambio, ven aparecer algunos enclaves que son testimonio también de la dispersión de las clases medias, tradicionales y nuevas, por el territorio metropolitano, pero sin las dimensiones que alcanza la periferización de las clases medias en Barcelona o Madrid. En el caso de Sevilla, se produce en las principales zonas de expansión de la metrópolis, en municipios del sur y occidentales, como San Juan de Aznalfarache, Gelves y Mairena de Aljarafe, Tomares, Camas, Gines y Valencina de la Concepción. En Valencia, más allá del centro metropolitano, surgen áreas de nuevas clases medias en zonas de baja densidad costeras, en los poblados marítimos de la Albufera, y en las urbanizaciones costeras de los municipios de la Pobla de Farnals y Puig. En el interior, algunas urbanizaciones de baja densidad como las exclusivas Santa Bárbara en Rocafort, o Tancat de l'Alter en Picassent. Por último, en Bilbao destaca la consolidación y crecimiento de las áreas residenciales de clases medias y altas en la margen derecha de la ría de Nervión, en el municipio de Getxo, extendiéndose por el litoral, pero también desta-

52 Las áreas suburbanas, en este análisis, tienen una parte efímera que tiene que ver con uno de sus rasgos principales que es la falta de arraigo de sus residentes. Su carácter está definido en gran parte por la llegada reciente de familias con hijos que acceden a una vivienda en propiedad, habitualmente en la periferia. Pero a medida, que pasa el tiempo y los residentes en estas áreas van dejando de ser "recién llegados", el área socio-residencial cambia de carácter. 
ca la colonización de la margen izquierda de la ría a través del puente de Bizcaia en un pequeño enclave entre los municipios de Santurce y Portugalete.

Una tercera idea a destacar es la proliferación de áreas suburbanas en las periferias, a excepción de Barcelona. Esta es la única metrópoli en que, como se ha visto en el gráfico 6, las áreas suburbanas pierden peso. En las otras cuatro metrópolis, la periferia se muestra de manera clara como el espacio de acogida de familias con hijos, ámbitos que les permiten aspirar a la adquisición de una vivienda con una relación calidad-precio asumible mediante la formalización de una hipoteca.

Por último, un cuarto aspecto importante es la tendencia de las áreas degradadas a localizarse en espacios periféricos vulnerables. Si como se ha visto, las áreas de clases medias se han tendido a localizar en los centros metropolitanos y determinados espacios periféricos creados para su asentamiento, su reverso y complemento ha sido la dispersión de las áreas degradadas por multitud de enclaves fuera de las áreas centrales de las metrópolis estudiadas, donde se acumulan riesgos de vulnerabilidad y exclusión social. La incidencia de la crisis sobre poblaciones más vulnerables, tradicionalmente de clases trabajadoras, materializándose en un gran aumento del paro, así como la presencia de población extranjera con un bajo estatus socioeconómico en viviendas en régimen de alquiler, pueden ayudar a explicar este fenómeno. Otra hipótesis sobre la que trabajar es la de la suburbanización de la pobreza, es decir, el desplazamiento de población vulnerable a las periferias. La contrastación de ambas hipótesis excede los objetivos del presente artículo, no obstante se están realizando ya algunos análisis al respecto en España ${ }^{53}$.

Sobre el territorio, las áreas degradadas tan sólo ocupan espacios testimoniales en las áreas más céntricas de todas las metrópolis estudiadas, como en algunas secciones de los barrios del Raval, la Barceloneta o Sant Pere, Santa Caterina i la Ribera o el barrio de Poble Sec en Barcelona; en los barrios de Embajadores, Lavapiés, Justicia y Universidad en Madrid; el Carme en Valencia; los barrios de San Francisco, Bilbao la Vieja y Zabala en Bilbao; o el Casco Norte y los barrios de Alfalfa y San Bartolomé de Sevilla. No obstante, como se decía, la tendencia que presentan este tipo de áreas es a ocupar espacios periféricos de los municipios centrales y de otros municipios metropolitanos. En Barcelona, con una elevada dispersión por el territorio, pero definida en un primer plano por los ejes de los ríos Besòs y Llobregat en la primera corona metropolitana y, más allá, por la aparición en las principales ciudades de la segunda corona (Sabadell, Terrassa, Granollers, Mataró o Martorell). En el caso de Madrid, aparece una proliferación de áreas degradadas en torno al eje sureste (distritos de Carabanchel, Usera, Villaverde, Puente y Villa de Vallecas, Ciudad Lineal y San Blas), con algunas apariciones al norte (margen izquierda de la calle Bravo Murillo del distrito de Tetuán y algunas secciones en Moratalaz). Más allá del municipio de Madrid, también destacan en los municipios del cinturón rojo del sur y este. Valencia, por su parte, experimenta un crecimiento de este tipo de áreas degradadas alrededor del centro, en barrios del este y sur, como Cabanyal y Natza-

53 Porcel et al., 2018; Sorando y Leal, 2019. 
ret, en los distritos del este de Patraix y l'Oliveret, o al norte en Benicalap, Rascanya y Pobles del Nord. Además, también están apareciendo en algunas zonas de los municipios de la Horta Oest. En Sevilla, las áreas degradadas aparecen en las áreas destinadas a la residencia de las clases trabajadoras y vulnerables tradicionales del municipio central, como es el caso del Polígono Norte, Pino Montano, Parque Alcosa y Polígono San Pablo al norte; el área de Tres Barrios-Amate y el Cerro del Águila al este y el Polígono Sur en la zona meridional, mientras que prácticamente no tiene presencia fuera del municipio de Sevilla. Por último, el caso de Bilbao es especialmente interesante, no sólo por la aparición de numerosas áreas degradadas, proceso que también acontece en la metrópoli valenciana, sino por la dispersión territorial de las mismas. Este tipo de áreas socio-residenciales pasan de estar concentradas en la ciudad histórica, en torno a los barrios de Casco Viejo, Bilbao la Vieja, San Francisco, Zabala y en los barrios del norte de Arangoiti y Ibarrelokanda del distrito de Deusto, a estar presentes en prácticamente todos los distritos del municipio de Bilbao, expandiéndose más allá de los límites de la ciudad central, mayoritariamente por los municipios de tradición industrial de la margen izquierda de la ría de Bilbao (Santurce, Portugalete, Sestao, Baracaldo) y continuando hacia el sur por Alonsótegui, hasta llegar a Basauri.

En síntesis, la idea que subyace de este análisis detallado de las dinámicas socio-residenciales en las principales metrópolis españolas es que, en general, se está produciendo un proceso de aumento de la complejidad de las periferias metropolitanas. Esto supone un cambio significativo en lo que hasta ahora había sido la estructura socio-residencial más predominante en las metrópolis españolas, caracterizadas por un centro complejo y diverso en contraposición a unas periferias mucho más homogéneas. Como se ha podido observar, los procesos de fragmentación de la estructura socio-residencial que se han venido produciendo durante la última década se han traducido en la producción de unas periferias más diversas, mientras que las áreas céntricas han tendido a reducir su complejidad. Las clases medias, de diferente tipo, se hacen hegemónicas en los espacios centrales, minimizando o haciendo desaparecer las áreas degradadas - en esto, como se ha visto, Bilbao representa una excepción-. En cambio, en la periferia han proliferado todo un conjunto de áreas socio-residenciales diferenciadas. Por un lado, ha aumentado la presencia de áreas degradadas, al mismo tiempo que las clases medias se han extendido también más allá del centro metropolitano, aprovechando áreas propicias y generadas para su asentamiento. Además, otra fuente de diversificación de las periferias metropolitanas es el propio crecimiento urbano y el desarrollo de nuevas promociones de vivienda, un proceso en el que las áreas suburbanas se erigen como enclaves pioneros de colonización del territorio. En el futuro, estas áreas, compuestas predominantemente en un inicio por familias con hijos de reciente llegada, evolucionarán hacia tipos socio-residenciales más diversos, de clases medias, mixtos o degradados, en función de los perfiles sociales y residenciales de las mismas. De manera que es 
previsible que la complejidad de las periferias de las metrópolis españolas continúe aumentando en los próximos años.

\section{Principales aspectos asociados a la polarización socioresidencial}

Para acabar se ha realizado también un análisis sobre qué factores están más asociados con la dinámica de polarización socio-residencial que se está produciendo en las principales metrópolis españolas. Este análisis se ha realizado agrupando los factores en dos bloques. El primero, recoge los aspectos de carácter demográfico y geográfico, como el tamaño poblacional, la superficie y la densidad poblacional de la metrópolis. En el segundo, se recogen una serie de proxys que hacen referencia a los principales fenómenos estructurales contemplados en la literatura: la globalización o grado de internacionalización (a partir del porcentaje de población extranjera), la desindustrialización (a partir del porcentaje de ocupados en el sector servicios) y la crisis económica (a partir de la tasa de paro).

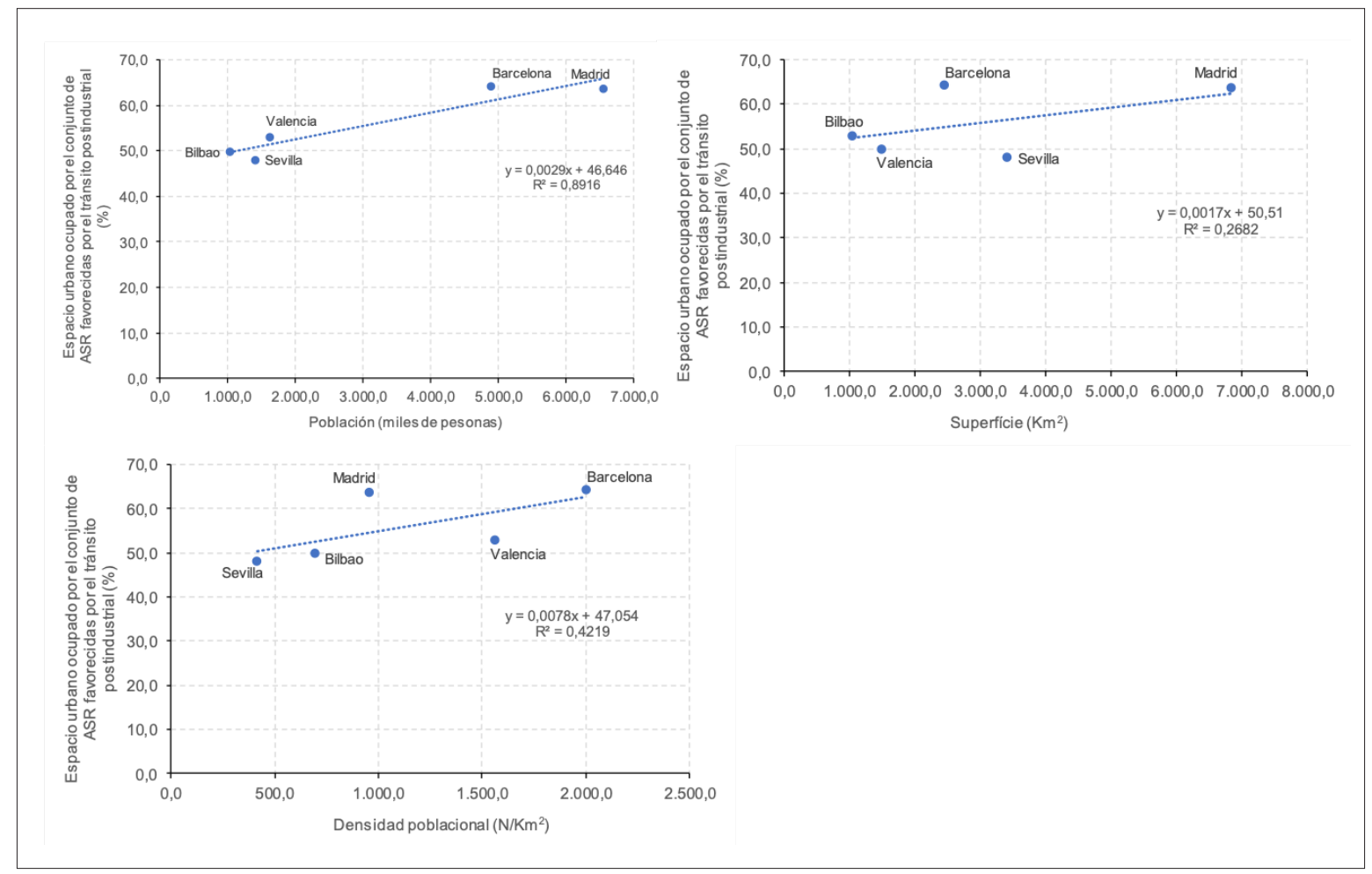

Gráfico 8. Correlación-dispersión entre el grado de polarización socio-residencial y el tamaño poblacional, la superficie y la densidad poblacional de la metrópolis. Metrópolis españolas, 2011

Fuente: elaboración propia a partir de datos del INE, Censo de Población y Viviendas, 2011 y INE, Urban Audit, 2011.

Por lo que respecta al primer bloque de análisis, tal y como se puede observar en el gráfico 8, los resultados indican que, sobre todo, es el tamaño poblacional de la metrópolis la característica que aparece más asociada a la dinámica de polarización socio-residencial. Son las metrópolis más pobladas y, por lo tanto, las que atraen más población, las que efectivamente se muestran más vulnerables a los procesos 
de fragmentación y de polarización socio-residencial. En este sentido, tanto Madrid como Barcelona, marcan la diferencia con 6,5 y 5 millones de habitantes respectivamente, mientras que el resto de metrópolis no alcanzan los 2 millones de habitantes. En cambio, ni la superficie ni la densidad de la metrópolis aparecen como factores relevantes en relación a la dinámica de polarización socio-residencial.

Los resultados del segundo bloque de análisis ponen de manifiesto que la proporción población extranjera y, por lo tanto, el grado de internacionalización de la población de la metrópolis, es el factor más asociado con la polarización socio-residencial. Esta idea resulta coherente con el propio modelo teórico de ciudad cuarteada, sin embargo, el otro supuesto teórico referente a la desindustrialización no se cumple según los datos analizados. La correlación que presenta el porcentaje de población ocupada en el sector servicios y el grado de polarización socio-residencial es muy baja, debido a que el conjunto de las metrópolis ya presenta un grado muy elevado de terciarización económica. Seguramente, con un poco más de perspectiva, para lo que se necesitaría una serie histórica de datos mucho más amplia de la que se dispone ${ }^{54}$, sí que sería posible encontrar una asociación más clara entre el proceso de desindustrialización y la polarización socio-residencial. Finalmente, también llama la atención que la tasa de paro correlaciona negativamente con este fenómeno

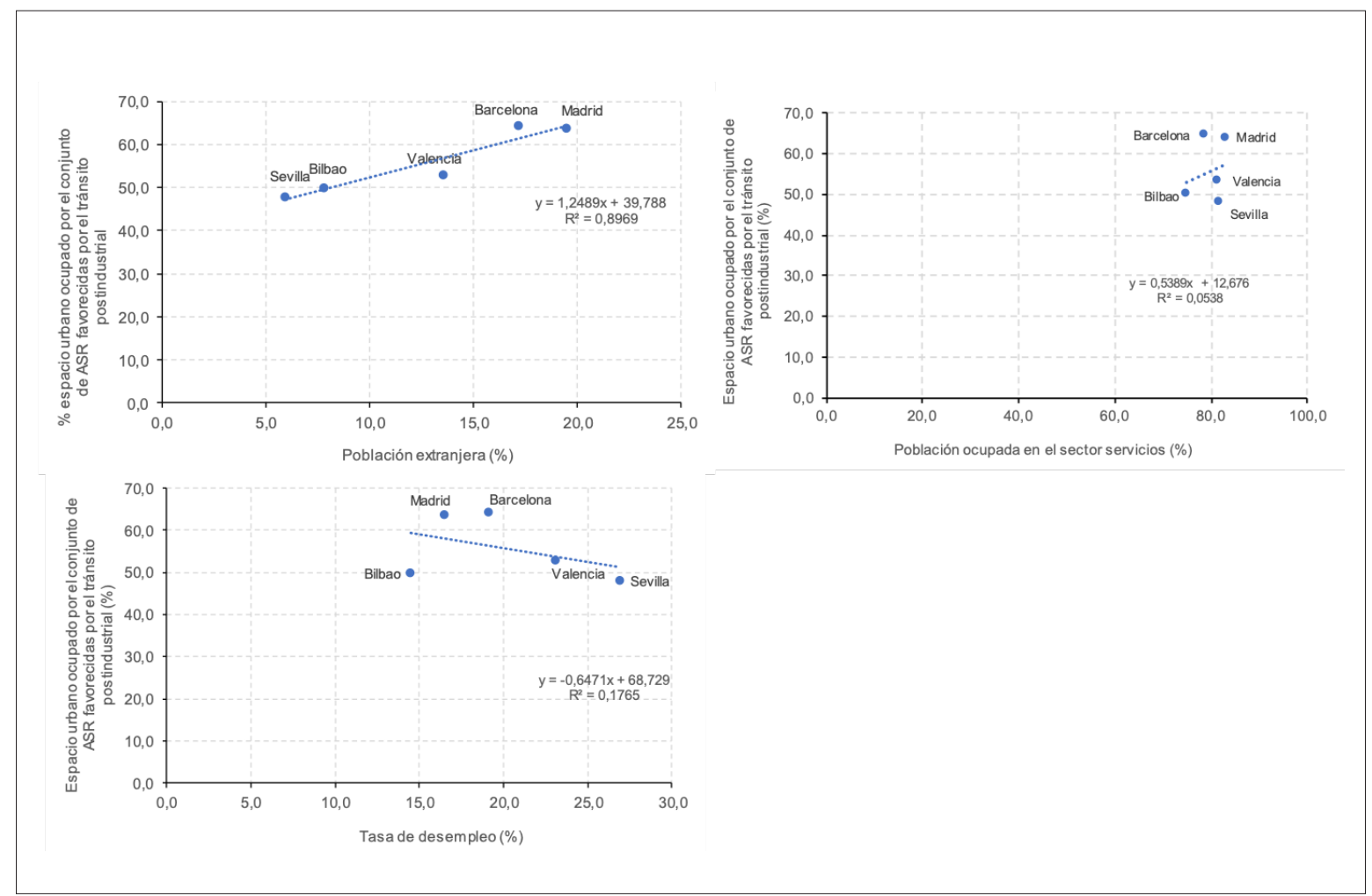

Gráfico 9. Correlación-dispersión entre el grado de polarización socio-residencial y la población extranjera, la población ocupada en el sector servicios y la tasa de paro de la metrópolis. Metrópolis españolas, 2011.

Fuente: elaboración propia a partir de datos del INE, Censo de Población y Viviendas, 2011 y INE, Urban Audit, 2011.

54 Por lo menos sería necesario disponer de datos desde principios de los años 80 que es cuando los procesos de desindustrialización empiezan a ganar intensidad en las ciudades españolas. 
socio-residencial, de lo que se deduce que el impacto de la crisis económica no ha jugado un papel relevante en los procesos de polarización socio-residencial, al menos a corto plazo. La elevada proporción de propietarios de vivienda que caracteriza las ciudades españolas podría explicar en parte esta circunstancia, mostrando una mayor rigidez al cambio residencial ante los ciclos económicos.

\section{Conclusiones}

La primera conclusión que se puede extraer de este trabajo es que la evolución de la estructuración socio-residencial de las principales metrópolis españolas sigue, a grandes rasgos, las pautas del modelo de ciudad cuarteada de Peter Marcuse. Tal y como se plantea en este modelo teórico, las metrópolis analizadas muestran un aumento - no generalizado- de la fragmentación de la estructura socio-residencial y una tendencia - generalizada - hacia la polarización socio-residencial. Estas dinámicas socio-residenciales se intensifican a medida que el tamaño poblacional y el grado de internacionalización de las urbes es más elevado. También se intuye que los procesos de desindustrialización, que han tenido lugar en las grandes ciudades españolas durante las últimas décadas, son un factor que favorece estas dinámicas socio-residenciales. No obstante, los datos disponibles no han permitido comprobar empíricamente esta cuestión de manera óptima. Todo esto explicaría por qué Madrid y Barcelona son actualmente las metrópolis más cuarteadas del contexto español. Se trata de las metrópolis que atraen más población y esta población es cada vez más diversa, tanto desde el punto de vista del origen como desde el punto de vista socioeconómico. Y, tal y como explica Marcuse ${ }^{55}$, la propia dinámica de distinción residencial que guía la localización residencial de los diferentes grupos sociales que habitan la ciudad, fragmentan cada vez más la urbe, aumentando también la desigualdad social entre los diferentes fragmentos urbanos.

En el contexto español, este proceso de cuarteamiento comporta diferentes procesos socio-residenciales que, salvando algunos matices y excepciones, se producen en todas las metrópolis analizadas. Uno de ellos es la expansión de las clases medias en los centros metropolitanos. Particularmente en los casos de Madrid, Barcelona y Valencia, este proceso es propiciado por la aparición también de nuevas clases medias. Este perfil social, habitualmente vinculado a los procesos de gentrificación, está compuesto predominantemente por población más bien joven, sin hijos, muchos de ellos extranjeros, muy cualificados y residentes en viviendas de alquiler.

Una segunda pauta socio-residencial es la dispersión de clases medias también en determinados enclaves de la periferia metropolitana, más allá de la ciudad central. Aunque este fenómeno no es tan novedoso como el que se ha señalado anteriormente, continúa siendo un proceso significativo en términos estructurales en las metrópolis estudiadas. En la misma línea, hay que destacar la aparición de áreas suburbanas, sobre todo en las metrópolis analizadas de menor tamaño: Bilbao, Valencia y Sevilla. El rasgo principal de este tipo de área socio-residencial es el poco

55 Marcuse, 1993; Marcuse y van Kempen, 2000, 2002. 
arraigo de sus habitantes. Se trata de familias relativamente jóvenes con hijos que han accedido recientemente a viviendas de propiedad en estas áreas (predominantemente periféricas), cuyo estatus socioeconómico es diverso. Finalmente, otro de los fenómenos socio-residenciales más relevantes que se han identificado en los análisis realizados es la localización periférica de áreas degradadas, las cuales han ido desapareciendo paulatinamente de los centros metropolitanos a medida que éstos han sido ocupados por las clases medias.

En síntesis, este conjunto de procesos socio-residenciales indican que las periferias metropolitanas españolas están incrementando su complejidad, al mismo tiempo que las áreas centrales tienden a disminuirla. Este doble fenómeno es relevante, ya que hasta ahora las metrópolis españolas se habían caracterizado por una mayor diversidad y complejidad de las áreas centrales, en contraposición a las periferias que eran más bien homogéneas desde el punto de vista socio-residencial. Esta transformación denota, entre otras cosas, un cambio de escala de las metrópolis españolas, donde los procesos de metropolitanización van avanzando y madurando. En este sentido, las ciudades centrales se ven cada vez más superadas por la realidad urbana, lo que plantea retos importantes de presente y de futuro en términos de gestión y de gobernanza de la ciudad real, sobre todo por lo que respecta a la planificación urbanística, a las políticas de acceso a la vivienda y de cohesión social, así como a las medidas relacionadas con la movilidad y con la reducción de la contaminación.

\section{Bibliografía}

ABRAHAMSON, M.; JOHNSON, P. The Social Ecology of Madrid: Stratification in Comparative Perspective. Demography, 1974, no 11, p. 521-532.

ANDERSEN, H. T. Social Change and Segregation in Copenhagen. GeoJournal, 1998, $\mathrm{n}^{\circ} 46$, p. 7-16.

AURTENETXE, J. Estructura urbana y diferenciación residencial: el caso de Bilbao. Madrid: Centro de Investigaciones Sociológicas, 1989.

BASULTO, J.; ARIAS, C. Un estudio sobre la diferenciación residencial en el espacio urbano de Sevilla. Ciudad y Territorio. Estudios Territoriales, 1989, n 79, p. 85-92.

CASTELLS, M.; MOLLENKOPF, J. Conclusion: Is New York a Dual City? En J. MOLLENKOPF; M. CASTELLS (Eds.), Dual City: Restructuring New York. Nueva York: The Russell Sage Foundation, 1991, p. 399-418.

CHECA, J. C. La diferenciación residencial: Conceptos y modelos empíricos para su comprensión. Granada: Editorial Comares, 2006.

COSTA, M.; PORCEL, S. L'estructura socioespacial de la regió metropolitana de Barcelona des d'una aproximació multimètode. Una proposta metodològica per a l'estudi de la diferenciació socioresidencial. Documents d'Anàlisi Geogràfica, 2013, vol. 59, n 2, p. 315-345.

DEL CAMPO, A. Una aplicación de Ecología Factorial al estudio de pautas espaciales de segregación social en el municipio de Madrid. Ciudad Y Territorio. Estudios Territoriales, 1983, nº 57-58, p. 137-154. 
DÍAZ, M.Á. Alcalá de Henares: la diferenciación residencial en una ciudad histórica del área metropolitana de Madrid. Anales de Geografía de la Univeridad Complutense, 1986, nº 6. 253-272.

DÍAZ, M. Á. Los estudios de ecología factorial urbana en España. Una aproximación al análisis comparativo. Norba. Revista De Geografía, 1989, no 8-9, p. 697-708.

DUHAU, E.; GIGLIA, Á. Las reglas del desorden: habitar la metrópoli. México D.F.: Siglo XXI, 2008.

ESPING-ANDERSEN, G. The Three Worlds of Welfare Capitalism. Cambridge: Polity, 1990.

FERNÁNDEZ, F. Geografía factorial del área urbana de Granada. Granada: Universidad de Granada, 1978.

FERRAS, R. Barcelone: croissance d'une métropole. Paris: Anthropos, 1977.

FLORIDA, R. The New Urban Crisis: how our crisis are increasing inequality, deppening segregation, and failing the middle class - and what we can do about it. New York: Basic Books, 2017.

GALEANO, J. M.; SABATER, A.; DOMINGO, A. Formació i evolució dels enclavaments ètnics a Catalunya abans i durant la crisi econòmica. Documents d'Anàlisi Geogràfica, 2014, vol. 60, n², p. 261-288.

GANS, H. The Urban Villagers: Group and social class in the life of italo-americans. Nueva York: The Free Press, 1962.

HAMNETT, C. Social Polarisation in Global Cities: Theory and Evidence. Urban Studies, 1994, vol. 31, no 3, p. 401-424.

HARLOE, M.; FAINSTEIN, S. S. Conclusion: The divided cities. En S. S. FAINSTEIN; I. GORDON; M. HARLOE (Eds.), Divided Cities: New York \& London in the Contemporary World. Oxford: Blackwell, 1992, p. 236-268.

HATZ, G. Features and Dynamics of Socio-Spatial Differentiation in Vienna and the Vienna Metropolitan Region. Tijdschrift Voor Economische en Sociale Geografie, 2009, vol. 100, nº 4, p. 485-501.

JIMÉNEZ-BLASCO, B. C. Aproximación metodológica al estudio de la diferenciación residencial urbana en Madrid. Anales de Geografía de la Univeridad Complutense, 1984, no 4, p. 167-187.

LOZARES, C.; DOMÍNGUEZ, M. Enquesta de la Regió de Barcelona. Territori i realitat social:les zones socio-demogràfiques de la RMB. Barcelona: Diputació de Barcelona, Mancomunitat de Municipis de l'Àrea Metropolitana de Barcelona, Institut d'Estudis Regionals i Metropolitans de Barcelona, 1993.

LOZARES, C.; DOMÍNGUEZ, M. Tratamiento multivariado de subpoblaciones en una gran encuesta social: la construcción de zonas sociales. Papers, 1996, n 48, p. $71-87$.

LOZARES, C.; LÓPEZ-ROLDÁN, P.; FLORES, J. L. Enquesta de la Regió de Barcelona. Zones socials. Barcelona: Diputació de Barcelona, Mancomunitat de Municipis de l'Àrea Metropolitana de Barcelona, Institut d'Estudis Regionals i Metropolitans de Barcelona, 2003. 
MARCUSE, P. "Dual city": a muddy metaphor for a quartered city. International Journal of Urban and Regional Research, 1989, vol. 13, nº 4, p. 697-708.

MARCUSE, P. What's So New About Divided Cities? International Journal of Urban and Regional Research, 1993, vol. 17, n 3, p. 355-365.

MARCUSE, P. Space and Race in the Post-Fordist City: Tha Outcast Ghetto and Avanced Homelessness in the United States Today. En E. MINGIONE (Ed.), Urban Poverty and the Underclass: A Reader. Oxford: Blackwell, 1996, p. 176-216.

MARCUSE, P.; VAN KEMPEN, R. Conclusion: A Changed Spatial Order. En P. MARCUSE; R. VAN KEMPEN (Eds.), Globalizing Cities: A New Spatial Order? Oxford: Blackwell, 2000, p. 249-275.

MARCUSE, P.; VAN KEMPEN, R. States, Cities, and the Partitioning of Urban Space: Conclusions. En P. MARCUSE; R. VAN KEMPEN (Eds.), Of States and Cities: The Partitioning of Urban Space. Oxford: Oxford University Press, 2002, p. 258-268.

MARTORI, J. C.; APPARICIO, P. Changes in Spatial Patterns Of The Immigrant Population Of A Southern European Metropolis: The Case Of The Barcelona Metropolitan Area (2001-2008). Tijdschrift Voor Economische en Sociale Geografie, 2011 , vol. 102, nº 5, p. 562-581.

MASSEY, D. S.; DENTON, N. A. American Apartheid: Segregation and the making of the underclass. Cambridge: Harvard University Press, 1993.

MEYER, S; LUNNAY, B. The Application of Abductive and Retroductive Inference for the Design and Analysis of Theory-Driven Sociological Research. Sociological Research Online, 2013, vol. 18, n 1, p. 1-12.

MUSTERD, S. A Rising European Underclass? Social Polarization and Spatial Segregation in European Cities. Built Environment, 1994, vol. 20, no 3, p. 184-194.

MUSTERD, S.; OSTENDORF, W. Segregation, Polarisation and Social Exclusion in Metropolitan Areas. En S. MUSTERD; W. OSTENDORF (Eds.), Urban Segregation and the Welfare State. Londres: Routledge, 1998, p. 1-14.

OCAÑA, C. Estructuras demográficas y áreas sociales de la ciudad de Málaga. Sevilla: Junta de Andalucía, 1988.

PÉREZ, E.; SANTOS, C. Diferenciación socioespacial en la Zona Metropolitana de la Ciudad de México. Investigaciones Geográficas, 201 1, no 74, p. 92-116.

PORCEL, S. Desigualdad social y segregación residencial, una relación compleja Madrid: Fundación FOESSA, 2020.

PORCEL, S.; NAVARRO-VARAS, L.; ANTÓN-ALONSO, F.; CRUZ, I. La suburbanització de la pobresa com a efecte metropolità de la gentrificació: el cas de Barcelona. Papers. Regió Metropolitana de Barcelona, 2018, nº 60, p. 94-113.

PRÉTECEILLE, E. L'evolution de la segregation sociale et des inegalites urbaines: Le cas de la metropole parisienne. The Greek Review of Social Research, 2004, no 113 , p. 105-120.

RAGHUNATHAN, T. E.; LEPKOWSKI, J. M.; VAN HOEWYK, J.; SOLENBERGER, P. A Multivariate Technique for Multiply Imputing Missing Values Using a Sequence of Regression Models. Survey Methodology, 2001, vol. 27, no 1, p. 85-95. 
RODRÍGUEZ, M. J. Modelos sociodemográficos: Atlas Social de la Ciudad de Alicante. Tesis doctoral, Departamento de Sociología I y Teoría de la Educación, Universitat d'Alacant, 2000.

SASSEN, S. The Global City: New York, London, Tokyo. Princeton: Princeton University Press, 1991.

SASSEN, S. Cities in a World Economy. Thousand Oaks: Pine Forge Press, 1994.

SASSEN, S. Service Employment Regimes and the New Inequality. En E. MINGIONE (Ed.), Urban Poverty and the Underclass: A Reader. Oxford: Blackwell, 1996, p. 6482.

SOLÀ-MORALES, M. Factorialización de caracteristicas de un área suburbana. Revista de Geografía, 1970, vol. 4, n 2, p. 159-186.

SORANDO, D.; ARDURA, A. First We Take Manhattan: La destrucción creativa de las ciudades. Madrid: Catarata, 2016.

SORANDO, D.; LEAL, J. Distantes y desiguales: el declive de la mezcla social en Barcelona y Madrid. Revista Española de Investigaciones Sociológicas, 2019, nº 167, p. 125-148.

SUTTLES, G. The social order of slum: ethnicity and territory in the inner city. Chicago: The University Chicago Press, 1968.

TAMMARU, T.; MARCINCZAK, S.; VAN HAM, M.; MUSTERD, S. (Eds.) Socio-Economic Segregation in European Capital Cities: East Meets West. Abingdon: Routledge, 2016.

TIMMS, D. The Urban Mosaic: Towards a Theory of Residential Differentiation. Oxford: Cambridge University Press, 1975.

VAN DER WUSTEN, H.; MUSTERD, S. Welfare State Effects on Inequality and Segregation: Concluding remarks. En S. MUSTERD; W. OSTENDORF (Eds.), Urban Segregation and the Welfare State: Inequality and exclusion in western cities. Londres: Routledge, 1998, p. 238-247.

VAN KEMPEN, E. The Dual City and the Poor: Social Polarisation, Social Segregation and Life Chances. Urban Studies, 1994, vol. 31, nº 7, p. 995-1015.

WACQUANT, L. Parias urbanos: marginalidad en la ciudad a comienzos del milenio. Buenos Aires: Manantial, 2001.

WILSON, W. J. The Truly Disavantaged: The Inner City, The Underclass, and Public Policy. Chicago: The University Chicago Press, 1987. 


\section{Anexo estadístico}

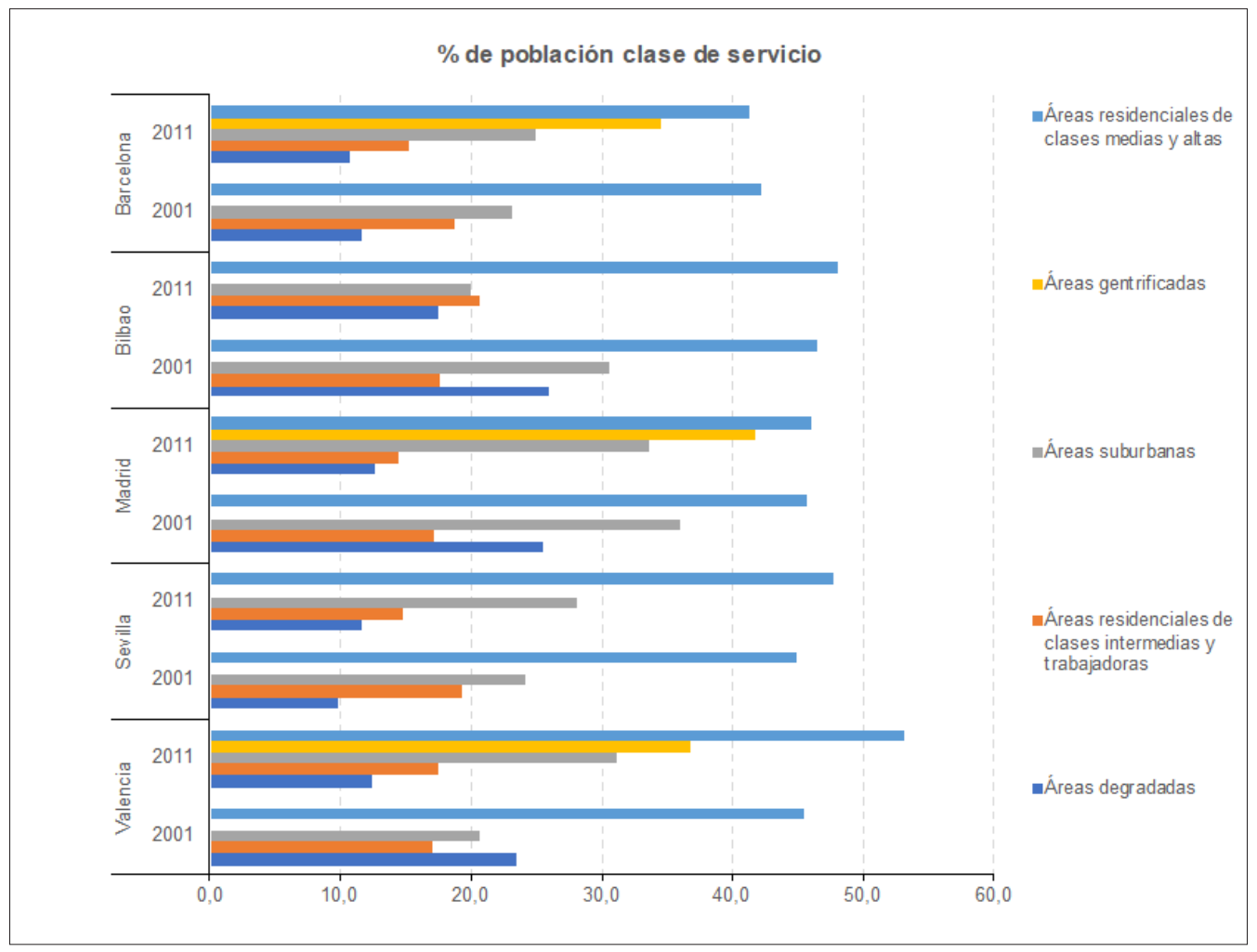

Gráfico A1. Población de clase media (profesionales y directivos) según áreas socio-residenciales. Población ocupada. Metrópolis españolas, 2001-2011

Fuente: elaboración propia a partir de datos del INE, Censo de Población y Viviendas, 2001-2011.

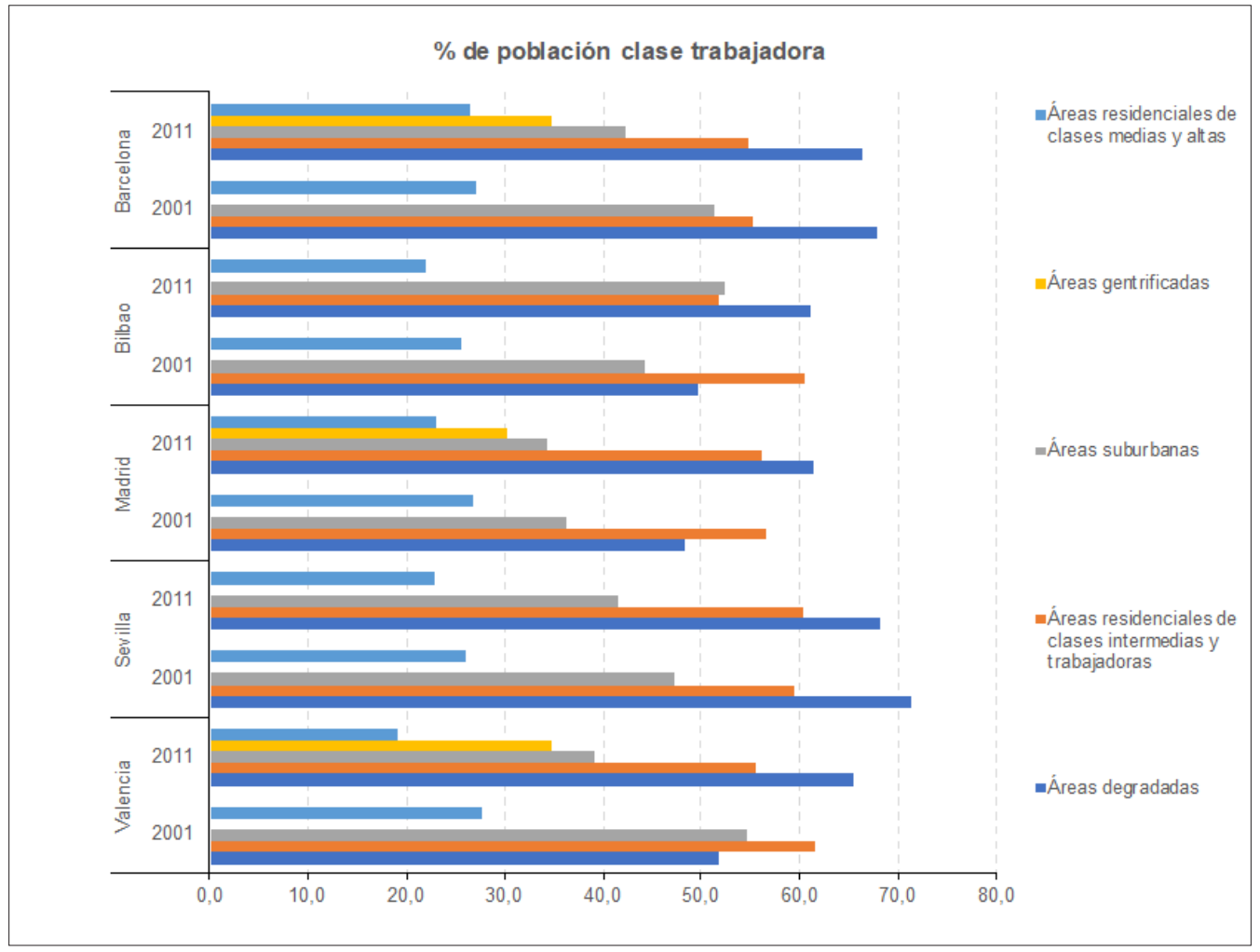

Gráfico A2. Población de clase trabajadora según áreas socio-residenciales. Población ocupada. Metrópolis españolas, 2001-2011F

Fuente: elaboración propia a partir de datos del INE, Censo de Población y Viviendas, 2001-2011. 


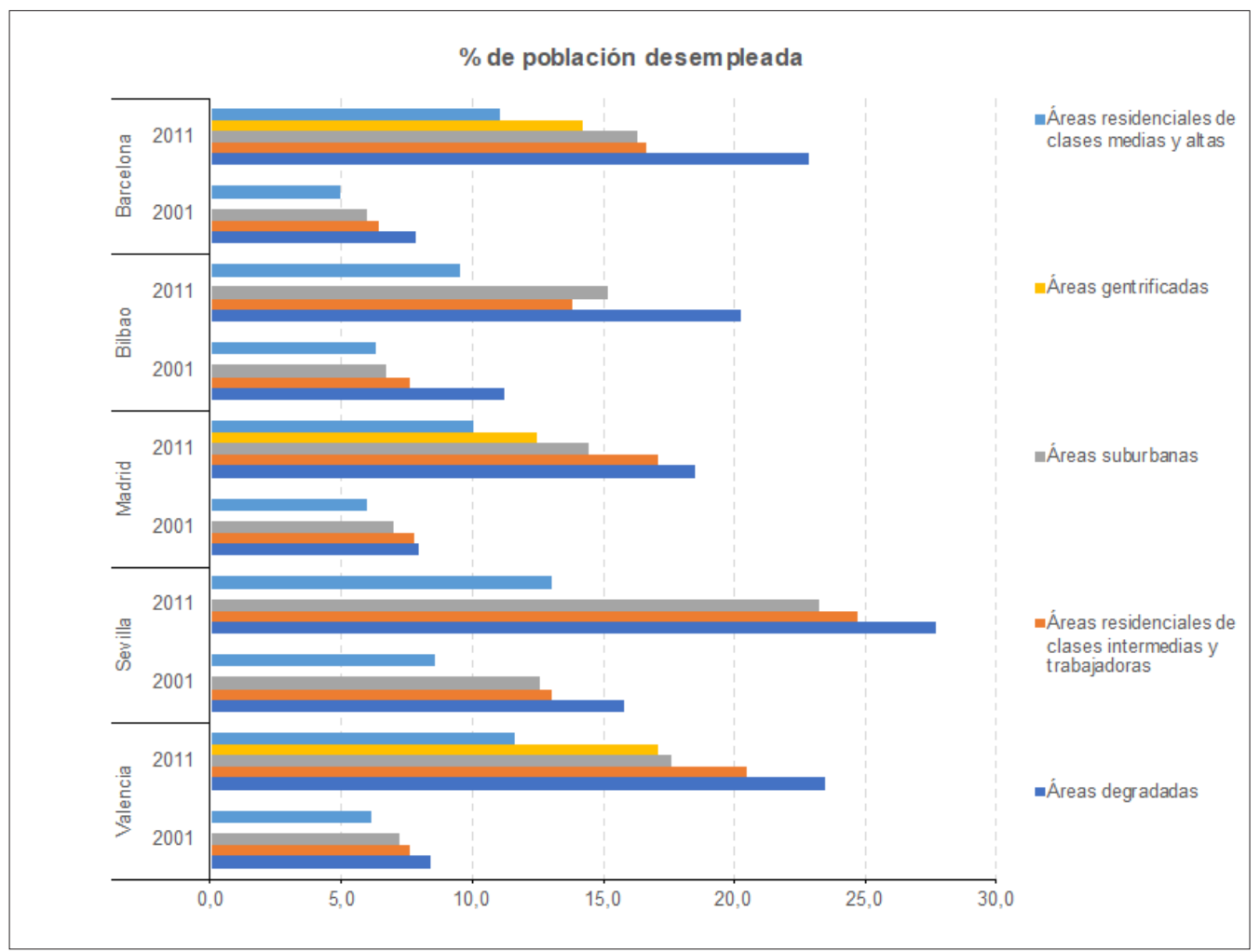

Gráfico A3. Población parada según áreas socio-residenciales. Metrópolis españolas, 2001-2011

Fuente: elaboración propia a partir de datos del INE, Censo de Población y Viviendas, 2001-2011.

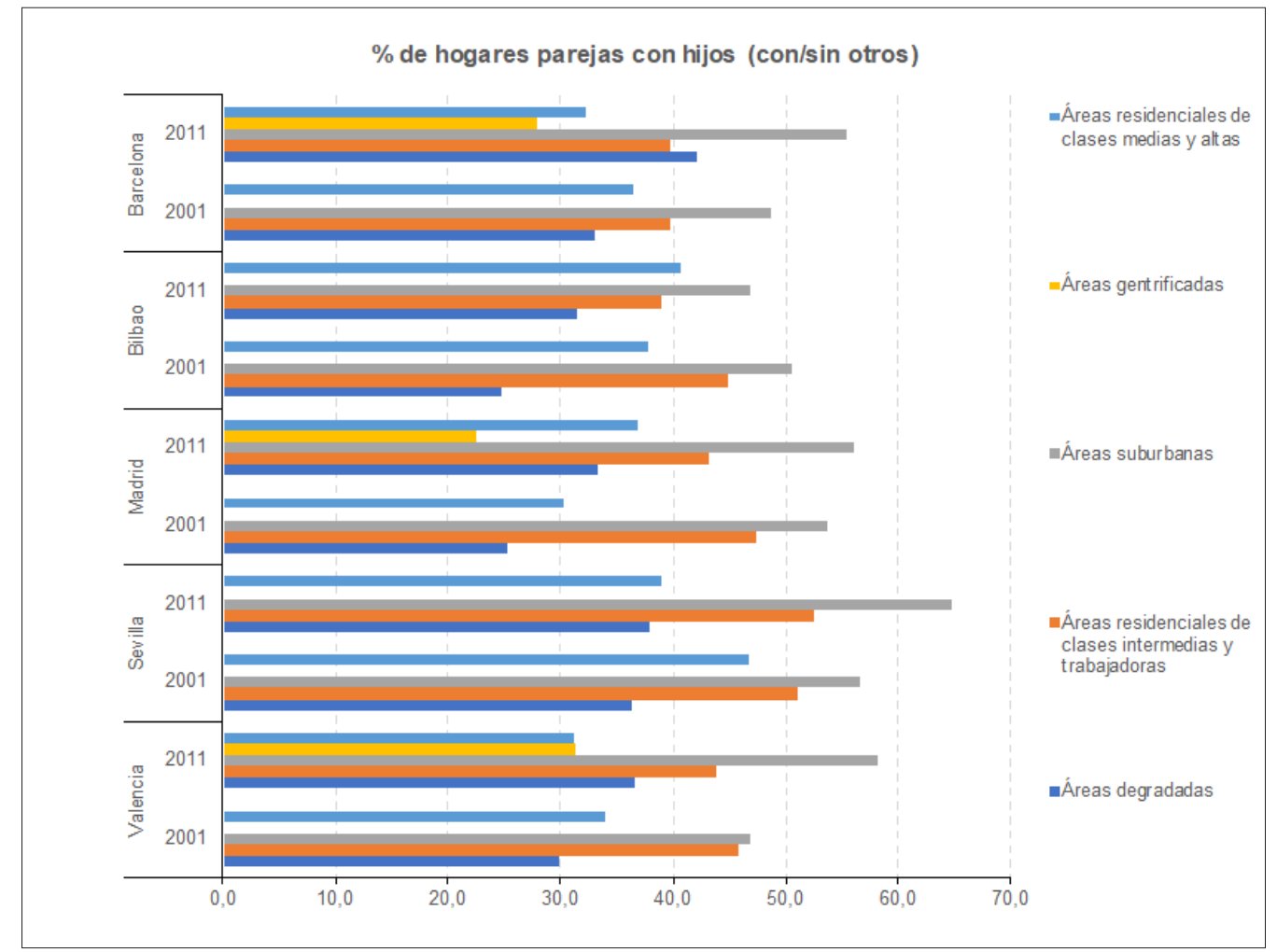

Gráfico A4. Parejas con hijos según áreas socio-residenciales. Metrópolis españolas, 2001-2011

Fuente: elaboración propia a partir de datos del INE, Censo de Población y Viviendas, 2001-2011. 


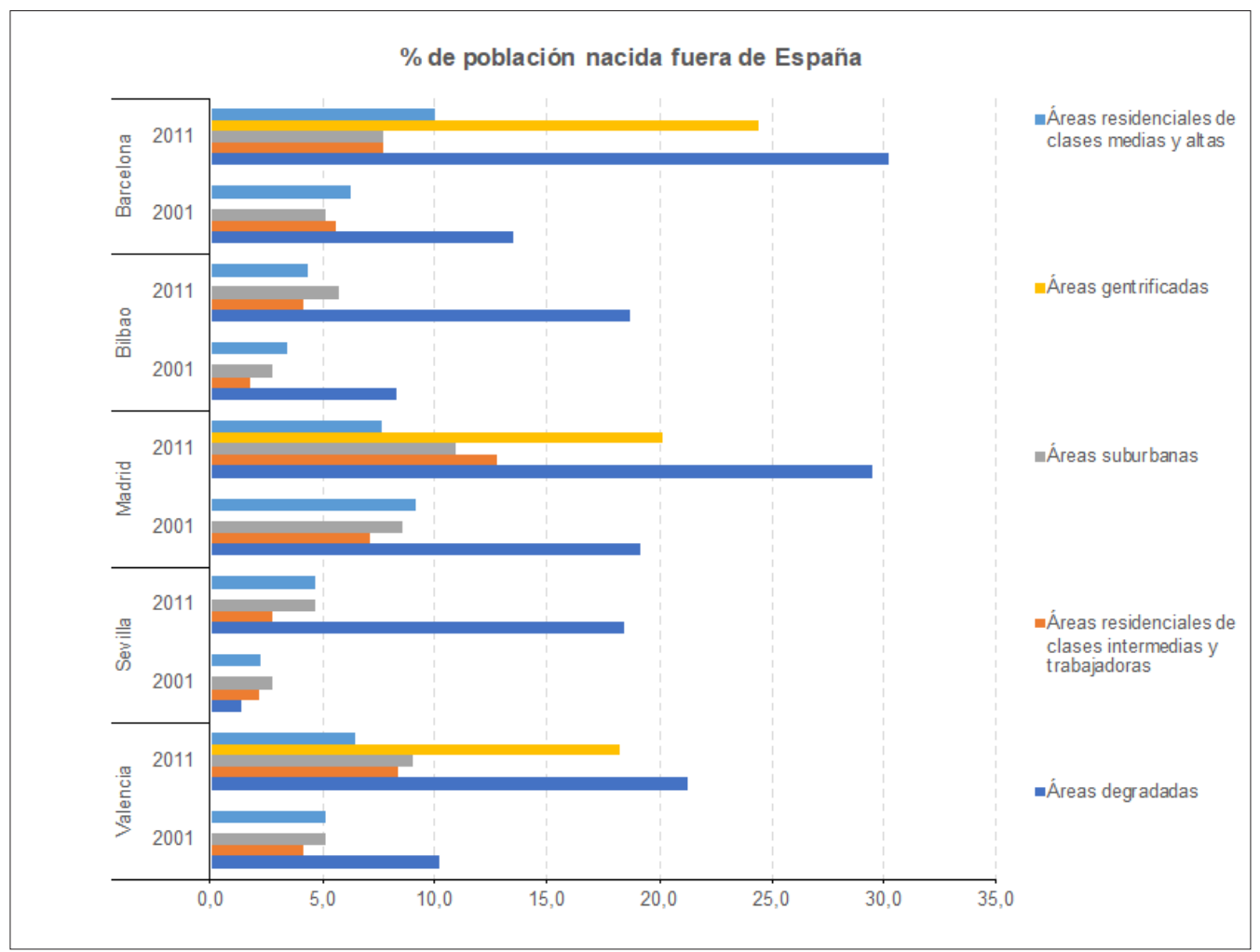

Gráfico A5. Población extranjera según áreas socio-residenciales. Metrópolis españolas, 2001-2011

Fuente: elaboración propia a partir de datos del INE, Censo de Población y Viviendas, 2001-2011.

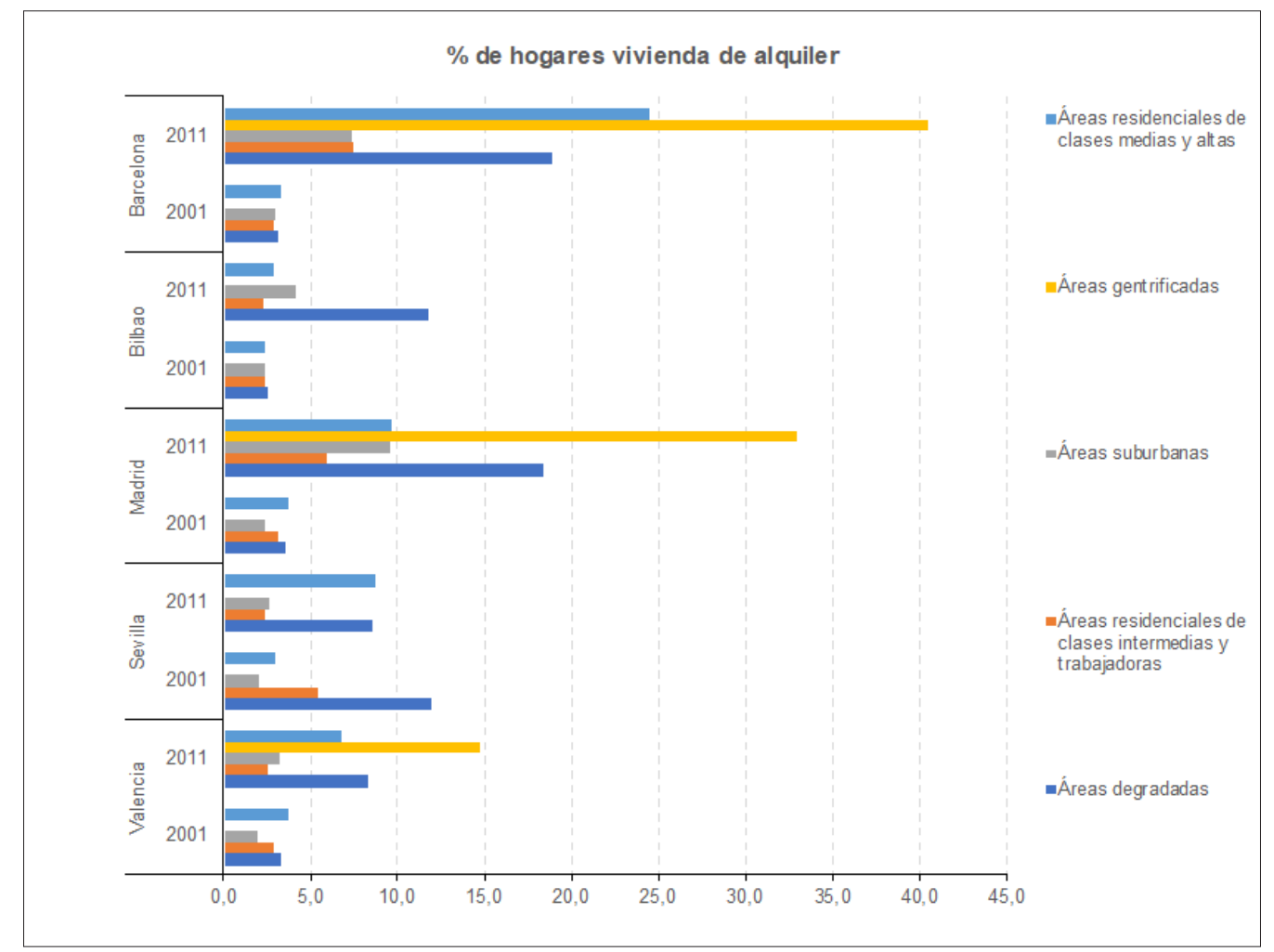

Gráfico A6. Hogares residiendo en viviendas de alquiler según áreas socio-residenciales. Metrópolis españolas, 2001-2011

Fuente: elaboración propia a partir de datos del INE, Censo de Población y Viviendas, 2001-2011. 


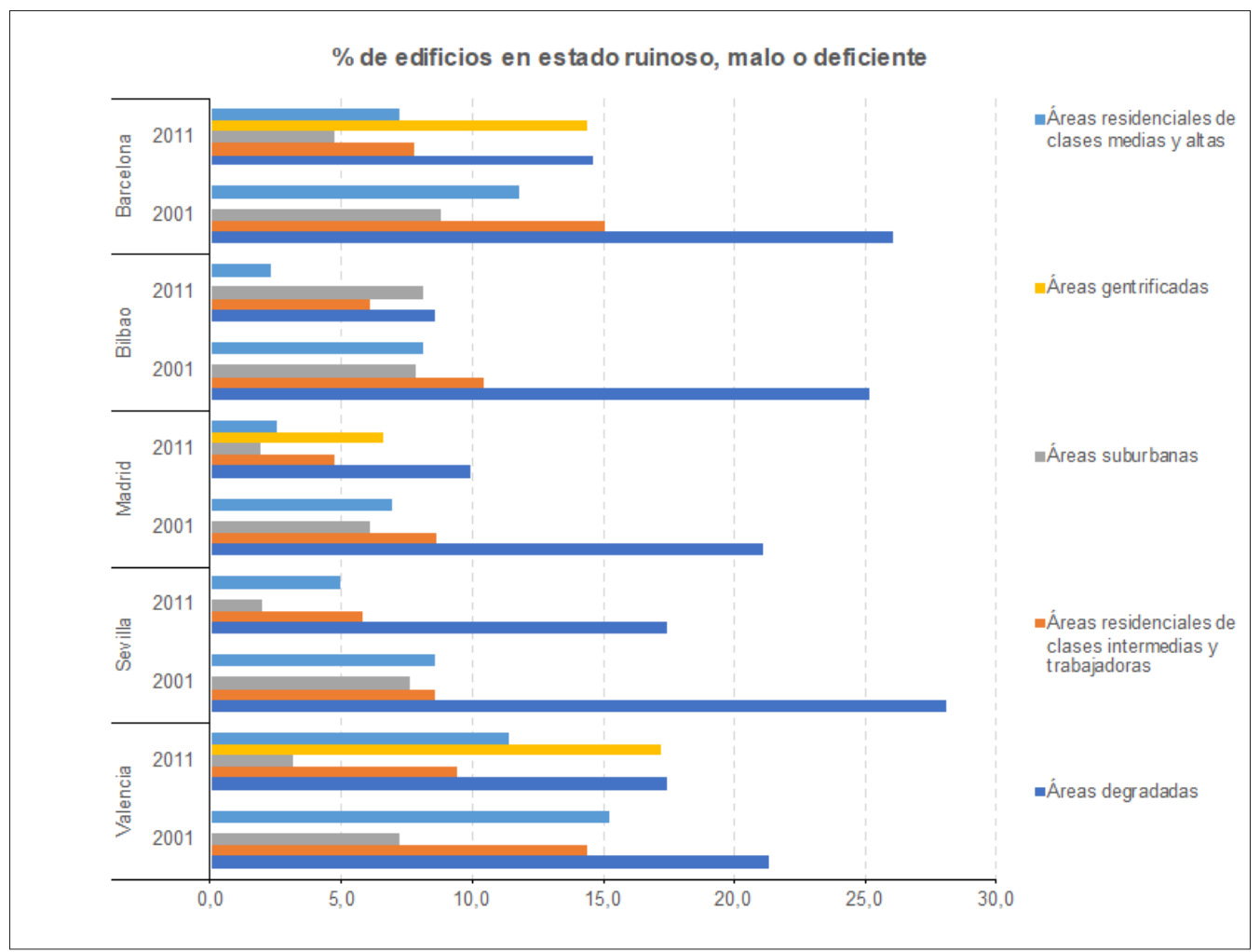

Gráfico A7. Edificios en mal estado según áreas socio-residenciales. Metrópolis españolas, 2001-2011

Fuente: elaboración propia a partir de datos del INE, Censo de Población y Viviendas, 2001-2011.

(C) Copyright: Sergio Porcel y Fernando Antón, 2020

(c) Copyright: Scripta Nova, 2020.

Ficha bibliográfica:

PORCEL, Sergio; ANTÓN, Fernando. Ciudad postindustrial y dinámicas socio-residenciales en España: un análisis comparativo de cinco metrópolis. Scripta Nova. Revista Electrónica de Geografía y Ciencias Sociales. Barcelona: Universidad de Barcelona, 1 de noviembre de 2020, vol. XXIV, nº 649. [ISSN: 1138-9788] 